\title{
Nonlinear Vibration Analysis of a Rotating Disk-Beam System Subjected to Dry Friction
}

\author{
Houxin She, ${ }^{1}$ Chaofeng Li $\mathbb{D}^{1,2}$ Qiansheng Tang, ${ }^{1}$ and Bangchun Wen ${ }^{1,2}$ \\ ${ }^{1}$ School of Mechanical Engineering and Automation, Northeastern University, Shenyang 110819, China \\ ${ }^{2}$ Key Laboratory of Vibration and Control of Aero-Propulsion System Ministry of Education, Northeastern University, \\ Shenyang 110819, China \\ Correspondence should be addressed to Chaofeng Li; chfli@mail.neu.edu.cn
}

Received 5 September 2019; Accepted 17 January 2020; Published 14 February 2020

Academic Editor: Francesco Pellicano

Copyright (C) 2020 Houxin She et al. This is an open access article distributed under the Creative Commons Attribution License, which permits unrestricted use, distribution, and reproduction in any medium, provided the original work is properly cited.

\begin{abstract}
In this work, a continuum model is proposed to simulate and interpret the coupling vibration characteristics of a rotating diskbeam system with the dovetail interfaces. The dovetail interface feature is represented by a macroslip dry friction model. The present study also derives a new mode function to simulate the vibration of a rotating beam with loosely assembled dovetail attachment. The new proposed mode function is validated by comparing the natural characteristics and vibration response with those obtained from a finite element (FE) model. At last, based on the nonlinear response results obtained by the Newmark- $\beta$ method, the effects of different parameters on the nonlinear dynamics of the coupling system are discussed. The following interesting phenomena have been revealed: the flexible disk can impose different influences on the response characteristics of the rotating beam. The effects of dry friction on the beam's energy dissipation are significant, especially at a low rotational speed. Further analysis yields that the excitation level and friction coefficient also exhibit a significant impact on the damping effect of dry friction. Consequently, it should be noted that the optimal values of the contact surface's parameters allow achieving a better damping effect in the engineering practice.
\end{abstract}

\section{Introduction}

In engineering practice, one of the most important nonlinear behaviors in a rotor system originates from the contact feature between different structures, which have been investigated by many scholars [1-4]. As for the blade system, dry friction damping is widely used to dissipate the unwanted vibration energy [5]. Therefore, the correct design of the blade system requires the capability to predict the nonlinear model characteristics effectively and accurately. In this context, the nonlinear dynamics of a rotating disk-beam system subjected to dry friction are presented and discussed carefully.

Friction damping is one of the economically and potentially effective solutions to dissipate the vibration energy of the blade system. Many scholars have investigated the dynamics of the system under the influence of friction damper. Macroslip model and microslip model are two different kinds of friction mechanism model of friction damper. Macroslip model is extensively used firstly [6-8], which assumes that the contact DOF is in either slipping state or sticking state. Then, a more realistic model is researched, which is microslip model $[9,10]$. The microslip model allows the local slipping in the friction element without gross slip. Besides, the microslip model is also supported by experimental results [11-13].

With the development of the research, many researchers found that the blade is usually coupled with the disk or shaft, producing various vibration modes. Li et al. [14-16] proposed a continuum model to study the coupling mechanism among shaft bending and blade bending and analyzed the nonlinear characteristics of the coupling system supported by the nonlinear suspension. For studying the nonlinear dynamics of the bladed disk system undergoing friction damper, the finite element (FE) models are also commonly used. Petrov and Ewins [17] 
developed an approach to study the multiharmonic forced response characteristics of the bladed disks subjected to nonlinear forces at the blade roots. Charleux et al. [18] investigated the impact of friction in blade attachments on the forced response both numerically and experimentally. Dovetail structures also attract the attention of some scholars. A method for nonlinear modal analysis of bladed disk with dovetail attachment was proposed [19]. Ma et al. [20] used a finite element (FE) model of the blade-disk structure with a dovetail connection to study the rubimpact response characteristics of the blade system. Krack et al. [21] addressed the vibration behavior of the bladed disk with the mechanical joints of dry friction. And Xu has also done some meaningful works in friction contact by experimental and numerical methods [22-26]. By using a one-way coupled method, Lassalle and Firrone [27] investigated the nonlinear aeroelastic phenomena of a bladed disk system with friction contacts. In addition to the finite element (FE) model, the lump parameter model of the bladed disk system with dry friction damper was also established by some scholars. A new friction model was developed firstly [28]. Then, a multiblade model was proposed to analyze the vibration characteristics of turbine blades with dry friction damper accurately and easily. Joannin et al. [29, 30] established a lumped-parameter model with dry friction to deal with the cyclic system's nonlinear characteristics by different new derived methods.

As can be seen from the previous reference, the existing researches simplify the disk-beam system as a lumpedparameter with nonlinear contact force. Therefore, the present study establishes a continuum disk-beam model to analyze the nonlinear coupling vibration among subcomponents. The corresponding nonlinear force of contact feature is simulated by an ideal dry friction model. Besides, a new mode function is derived to simulate the vibration of the rotating beam with the dovetail interface feature. By comparing the natural characteristics and vibration response of the derived beam with those obtained by the FE model, it indicates that the derived mode function can simulate the vibration of the rotating beam with the contact feature well. At last, the derived continuum model is adopted to study the nonlinear characteristics of the rotating beam with a dovetail interface, considering the coupling effects among subcomponents. And the influence of different parameters on dry friction damping effect is obtained to provide a reference for the design in engineering practice.

\section{Mathematical Model}

Considering the coupling effects among the flexible disk and the rotating beam, the schematic diagram of the rotating disk- $N_{\mathrm{b}}$ beams system is introduced in Figure 1(a). A single sector of the disk-beam system with a dovetail interface feature is illustrated in Figure 1(b). In Figure 1, OXY is the global coordinate, and $o_{\mathrm{b}} x_{\mathrm{b}} y_{\mathrm{b}}$ represents the local coordinate system of the rotating beam.

The mathematical model of the rotating diskbeam system is established based on the following assumptions:

(1) It is assumed that the material of the coupling system is homogeneous, isotropic, elastic, and Hookean

(2) A macroslip dry friction model is used in representing the dovetail interface feature between beam root and disk

(3) The rotating beam is described using the derived mode function, considering the boundary condition of the tenon structure

(4) The flexibility of the shaft is neglected to simplify the coupling model

2.1. Mathematical Formulation of the Rotating Disk-Beam System. According to [31], the energy expression of the flexible disk and the $i^{\text {th }}$ rotating beam can be described as

$$
\begin{aligned}
& T_{\mathrm{D}}=\frac{1}{2} \rho_{\mathrm{D}} h_{\mathrm{D}} \int_{0}^{2 \pi} \int_{R_{\mathrm{s}}}^{R_{\mathrm{D}}}\left(\frac{\mathrm{D} \mathbf{r}_{\mathrm{OD}}}{\mathrm{D} t}\right)^{2} r \mathrm{~d} r \mathrm{~d} \theta=\frac{1}{2} \rho_{\mathrm{D}} h_{\mathrm{D}} \int_{0}^{2 \pi} \int_{R_{\mathrm{s}}}^{R_{\mathrm{D}}}\left(\frac{\mathrm{D} u_{\mathrm{D}}}{\mathrm{D} t}\right)^{2} r \mathrm{~d} r \mathrm{~d} \theta+\frac{1}{2} J_{\mathrm{pd}} \Omega^{2}, \\
& U_{\mathrm{D}}=\frac{1}{2} D \int_{0}^{2 \pi} \int_{R_{\mathrm{s}}}^{R_{\mathrm{D}}}\left\{\begin{array}{l}
\left(\nabla^{2} u_{\mathrm{D}}\right)^{2}+2\left(1-v_{\mathrm{D}}\right)\left[\frac{\partial}{\partial r}\left(\frac{1}{r} \frac{\partial u_{\mathrm{D}}}{\partial \theta}\right)\right]^{2} \\
-2\left(1-v_{\mathrm{D}}\right) \frac{\partial^{2} u_{\mathrm{D}}}{\partial r^{2}}\left(\frac{1}{r} \frac{\partial u_{\mathrm{D}}}{\partial r}+\frac{1}{r^{2}} \frac{\partial^{2} u_{\mathrm{D}}}{\partial \theta^{2}}\right)
\end{array}\right\} r \mathrm{~d} r \mathrm{~d} \theta+\frac{1}{2} \int_{0}^{2 \pi} \int_{R_{\mathrm{s}}}^{R_{\mathrm{D}}}\left[\sigma_{\mathrm{r}}\left(\frac{\partial u_{\mathrm{D}}}{\partial r}\right)^{2}+\sigma_{\theta}\left(\frac{1}{r} \frac{\partial u_{\mathrm{D}}}{\partial \theta}\right)^{2}\right] r \mathrm{~d} r \mathrm{~d} \theta,
\end{aligned}
$$




$$
\begin{aligned}
& T_{\mathrm{b}}=\frac{1}{2} \rho_{\mathrm{b}} A_{\mathrm{b}} \int_{0}^{L_{\mathrm{b}}}\left\{\begin{array}{c}
\left(\frac{\mathrm{D} u}{\mathrm{D} t}\right)^{2}+\left(\frac{\mathrm{D} v}{\mathrm{D} t}\right)^{2}+\left[\frac{\mathrm{D} u_{\mathrm{D}}\left(R_{\mathrm{D}}, \vartheta_{i}\right)}{\mathrm{D} t}\right]^{2}+x^{2}\left[\frac{\mathrm{D} u_{\mathrm{D}}^{\prime}\left(R_{\mathrm{D}}, \vartheta_{i}\right)}{\mathrm{D} t}\right]^{2} \\
+2 x\left[\frac{\mathrm{D} u_{\mathrm{D}}\left(R_{\mathrm{D}}, \vartheta_{i}\right)}{\mathrm{D} t}\right]\left[\frac{\mathrm{D} u_{\mathrm{D}}^{\prime}\left(R_{\mathrm{D}}, \vartheta_{i}\right)}{\mathrm{D} t}\right]-2\left[\frac{\mathrm{D} u_{\mathrm{D}}\left(R_{\mathrm{D}}, \vartheta_{i}\right)}{\mathrm{D} t}\right]\left(\frac{\mathrm{D} v}{\mathrm{D} t}\right) \cdot \sin \beta \\
-2 x\left[\frac{\mathrm{D} u_{\mathrm{D}}^{\prime}\left(R_{\mathrm{D}}, \vartheta_{i}\right)}{\mathrm{D} t}\right]\left(\frac{\mathrm{D} v}{\mathrm{D} t}\right) \cdot \sin \beta+2 \Omega\left\{u\left(\frac{\mathrm{D} v}{\mathrm{D} t}\right) \cos \beta-\left(\frac{\mathrm{D} u}{\mathrm{D} t}\right) v \cos \beta\right\} \\
+\Omega^{2}\left[u^{2}+v^{2}(\cos \beta)^{2}+2\left(R_{\mathrm{D}}+x\right) u_{\mathrm{D}}^{\prime} v \sin \beta\right]
\end{array}\right\} \mathrm{D} x, \\
& U_{\mathrm{b}}=\frac{1}{2} E_{\mathrm{b}} A_{\mathrm{b}} \int_{0}^{L_{\mathrm{b}}}\left(\frac{\partial u}{\partial x}\right)^{2} \mathrm{~d} x+\frac{1}{2} E_{\mathrm{b}} I_{\mathrm{b}} \int_{0}^{L_{\mathrm{b}}}\left(\frac{\partial^{2} v}{\partial x^{2}}\right)^{2} \mathrm{~d} x+\frac{1}{4} \rho_{\mathrm{b}} A_{\mathrm{b}} \Omega^{2} \int_{0}^{L_{\mathrm{b}}}\left[L_{\mathrm{b}}^{2}-x^{2}+2 R_{\mathrm{D}}\left(L_{\mathrm{b}}-x\right)\right]\left\{\left(\frac{\partial v_{b}}{\partial x}\right)^{2}+\left(\frac{\partial w_{b}}{\partial x}\right)^{2}\right\} \mathrm{d} x,
\end{aligned}
$$

where the specific meaning of the symbols in energy expression can be seen in the Appendix A or introduced in [31]. Besides, $v_{b}$ and $w_{b}$ are the beam's total displacements in the global coordinate, which can be given as

$$
\begin{aligned}
v_{\mathrm{b}} & =v-\left\{u_{\mathrm{D}}\left(R_{\mathrm{D}}, \vartheta_{i}\right)+x u_{\mathrm{D}}^{\prime}\left(R_{\mathrm{D}}, \vartheta_{i}\right)\right\} \sin \beta, \\
w_{\mathrm{b}} & =\left\{u_{\mathrm{D}}\left(R_{\mathrm{D}}, \vartheta_{i}\right)+x u_{\mathrm{D}}^{\prime}\left(R_{\mathrm{D}}, \vartheta_{i}\right)\right\} \cos \beta .
\end{aligned}
$$

\subsection{Mode Function of the Beam with the Dovetail Interface} Feature. When the rotating beam with the dovetail interface feature is working, the beam root is attached to disk under the influence of centrifugal force. In addition to the positive pressure on the contact surface, when the beam vibrates, the beam root and the flange occur at the relative motion, and the dry friction force occurs on the contact surface together. Dry friction plays a role in dissipating vibration energy, but dry friction on beam root is very complex. For describing the boundary conditions of the beam with the dovetail interface feature, the following simplification is given:

(1) Under the influence of centrifugal force, the contact surface of the beam root and disk keep in contact, and there is no separation phenomenon

(2) The effect of friction motion on the positive pressure of the contact surface is ignored

(3) In this paper, only the overall translational and bending vibrations of the beam are considered, and it is assumed that the torsion displacement of the beam root is small

According to the assumptions, the boundary of the beam is simplified as follows:

$$
\begin{array}{cl}
\text { Beam Root: } V^{\prime}(0)=0 & E_{\mathrm{b}} I_{\mathrm{b}} V^{\prime \prime}(0)=0, \\
\text { Beam Tip: } E_{\mathrm{b}} I_{\mathrm{b}} V^{\prime \prime}\left(L_{\mathrm{b}}\right)=0 & E_{\mathrm{b}} I_{\mathrm{b}} V^{\prime \prime \prime}\left(L_{\mathrm{b}}\right)=0,
\end{array}
$$

where $L_{\mathrm{b}}, E_{\mathrm{b}}$, and $I_{\mathrm{b}}$ are the beam length, Young modulus, and moment of inertia of beam, respectively.

The specific expression of the beam can be assumed as follows:

$$
V(x)=C_{1} \sin \alpha x+C_{2} \cos \alpha x+C_{3} \operatorname{sh} \alpha x+C_{4} \operatorname{ch} \alpha x,
$$

where $C_{1}, C_{2}, C_{3}$, and $C_{4}$ are integral constants.

Substituting equation (5) into equations (2) and (3), and then $\alpha$ is obtained by the numerical solution, and then substituting $\alpha$ into equation (5), the vibration mode function of the beam with dovetail interface feature is as follows:

$$
\begin{aligned}
V(x)= & \sin (\alpha x)-\sinh (\alpha x)-\left(\frac{\sin \left(\alpha L_{\mathrm{b}}\right)+\sinh \left(\alpha L_{\mathrm{b}}\right)}{\cos \left(\alpha L_{\mathrm{b}}\right)-\cosh \left(\alpha L_{\mathrm{b}}\right)}\right) \\
& \cdot[\cosh (\alpha x)+\cos (\alpha x)] .
\end{aligned}
$$

2.3. Matrix Notation of the Coupling System. The assumed mode method is employed in the present study, and the corresponding displacements of the coupling system can be stated as follows:

$$
\begin{aligned}
u & =\sum_{i=1}^{n_{\mathrm{b}}} U_{i}(x) q_{u i}(t)=\mathbf{U}(x) \mathbf{q}_{\mathrm{u}}(t), \\
v & =\sum_{i=1}^{n_{\mathrm{b}}} V_{i}(x) q_{v i}(t)=\mathbf{V}(x) \mathbf{q}_{\mathbf{v}}(t), \\
u_{\mathrm{D}} & =\sum_{m=0}^{m_{d}} \sum_{n=0}^{n_{d}} R_{m n}(r)\left[\cos (\mathrm{n} \theta) Q_{\mathrm{mn}}^{\mathrm{c}}(t)+\sin (\mathrm{n} \theta) Q_{\mathrm{mn}}^{\mathrm{s}}(t)\right] \\
& =\boldsymbol{\Phi}_{\mathrm{D}_{\mathrm{c}}}(r, \theta) \mathbf{Q}_{\xi}(t)+\boldsymbol{\Phi}_{\mathrm{D}_{\mathrm{s}}}(r, \theta) \mathbf{Q}_{\eta}(t) .
\end{aligned}
$$

Substituting equation (7) into the energy expressions and employment of the Lagrange equation, the motion equation in matrix notation is as follows:

$$
\mathbf{M} \frac{\mathrm{D}^{2} \mathbf{q}}{\mathrm{D} t^{2}}+(\mathbf{C}+\Omega \mathbf{G}) \frac{\mathrm{D} \mathbf{q}}{\mathrm{D} t}+\left(\mathbf{K}_{e}+\Omega^{2} \mathbf{K}_{\Omega}\right) \mathbf{q}=\mathbf{F}_{e}(t)-\mathbf{F}_{\mathrm{D}}(x, t),
$$

where $\mathbf{F}_{\mathrm{e}}(t)$ is the aerodynamic excitation, $\mathbf{F}_{\mathrm{D}}(x, t)$ is the nonlinear dry friction force, and the specific expression of the matrices can be seen in the Appendix B.

In this paper, the Rayleigh damping is adopted, and the specific expression is as follows: 


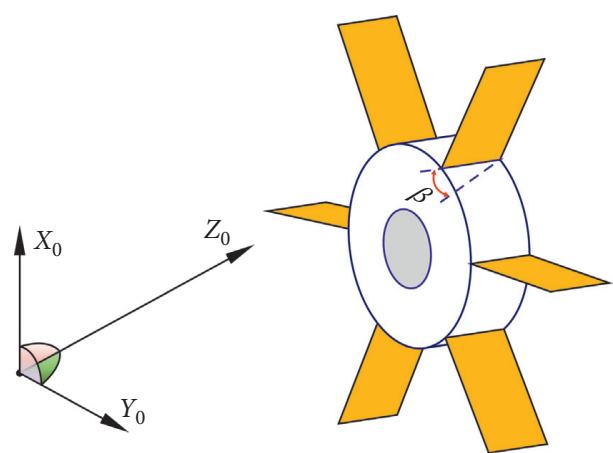

(a)

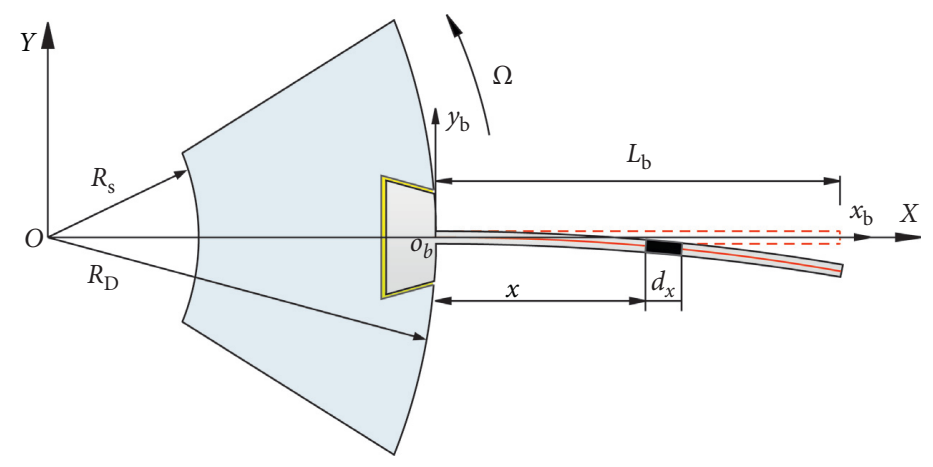

(b)

Figure 1: (a) Schematic diagram of a disk-beam structure. (b) A single sector of the disk-beam system with the dovetail interface feature.

$$
\begin{aligned}
\mathbf{C} & =\alpha \mathbf{M}+\beta \mathbf{K}_{e}, \\
\alpha & =\frac{2\left(\xi_{2} / \omega_{n 2}-\xi_{1} / \omega_{n 1}\right)}{\left(1 / \omega_{n 2}^{2}-1 / \omega_{n 1}^{2}\right)}, \\
\beta & =\frac{2\left(\xi_{2} \omega_{n 2}-\xi_{1} \omega_{n 1}\right)}{\omega_{n 2}^{2}-\omega_{n 1}^{2}},
\end{aligned}
$$

where $\omega_{\mathrm{n} 1}$ and $\omega_{\mathrm{n} 2}$ denote the first and second frequencies $(\mathrm{rad} / \mathrm{s})$ and $\xi_{1}$ and $\xi_{2}$ are the modal damping ratios of the first and second natural frequencies; here, $\xi_{1}=0.01$ and $\xi_{1}=0.02$.

\section{Mathematical Formulation of the Excitation Model}

3.1. Aerodynamic Excitation. The harmonic excitation is commonly used to represent the aerodynamic excitation, which naturally arises from the static parts in the gas flow. Here, the excitation is simplified as a simple harmonic wave [29]. Therefore, the harmonic excitation acting on the $i^{\text {th }}$ rotating-beam tip in this paper is given by equation (15).

$$
\mathbf{F}_{\mathrm{e}}^{i}(t)=\mathbf{H}(x) \cdot \delta\left(x-L_{\mathrm{b}}\right) \cdot F_{\mathrm{p}} \cdot \sin \left(\omega t+\frac{2 \pi}{N_{\mathrm{b}}}(i-1)\right)
$$

where $F_{\mathrm{p}}$ is the excitation amplitude, $\omega$ is the excitation frequency, $N_{\mathrm{b}}$ is the total number of the beams, and $\delta$ is the Dirac delta function.

$\mathbf{H}(x)$ is the mode function vector, and the specific expression is as follows:

$$
\mathbf{H}(x)=\left[\begin{array}{llll}
V_{1}(x) & \cdots & V_{n_{\mathrm{b}}}(x)
\end{array}\right]^{T},
$$

where $n_{\mathrm{b}}$ is the total number of blade bending modes, considered in the present study.

3.2. Friction Law. In this analysis, the corresponding contact interface diagram is illustrated in Figure 2. The present study implements a continuum mechanism model of the diskbeam system to investigate its nonlinear vibration characteristics, and the rotating beam is represented by the beam model. Therefore, as depicted in Figure 2, a point-surface contact model is employed. And the specific derivation of the time-discrete friction contact model is introduced in the following. A linear spring $k_{\mathrm{t}}$ in the tangential direction is used to model the local contact stiffness of the contact surface. According to the Coulomb friction law, the tangential force $f(t)$ under the normal force $N$ is derived by considering the relative tangential displacement of the contact DOF, named $u(t)$. Here, for focusing on the influence of contact interface on nonlinear coupling vibration, the normal force is assumed to be constant. In the present study, the specific expression of the normal force is $N=\rho_{\mathrm{b}} A_{\mathrm{b}} \Omega^{2} \int_{0}^{L_{\mathrm{b}}}\left(R_{\mathrm{D}}+x\right) \mathrm{D} x \cos \phi / \sin (\phi+\eta)$, generated by the centrifugal force of the beam system. The specific values of parameters are shown in Table 1.

After using a predictor step, the value of the tangential contact force under the sticking condition is as follows:

$$
T(t)=k_{\mathrm{t}}[u(t)-w(t-\Delta t)]
$$

where $\Delta t$ is the time step, $w(t)$ is the slider displacement, and $k_{\mathrm{t}}$ is the contact stiffness in the tangential direction; then, the actual value of tangential contact force is accordingly computed as

$$
f(t)= \begin{cases}T(t), & \text { stick state, } \\ \mu N(t) \operatorname{sign}(T(t)), & \text { slip state, }\end{cases}
$$

where $N(t)$ is the positive pressure of the contact surface. Besides, the slider displacement can be further obtained as

$$
w(t)= \begin{cases}w(t-\Delta t), & \text { stick state, } \\ u(t)-\mu N(t) \operatorname{sign}(T(t)) / k_{t}, & \text { slip state. }\end{cases}
$$

\section{Model Validation}

In this section, the mode function of a beam with the contact interface developed in Section 2.2 will be validated using the FE model. For simplicity, a simple beam system is adopted as the validation object. The vibration responses of the developed model and FE model in Ref. [8] are presented and compared to further validate the derived mode function. In this paper, the Rayleigh damping is adopted, as introduced in Section 2. 


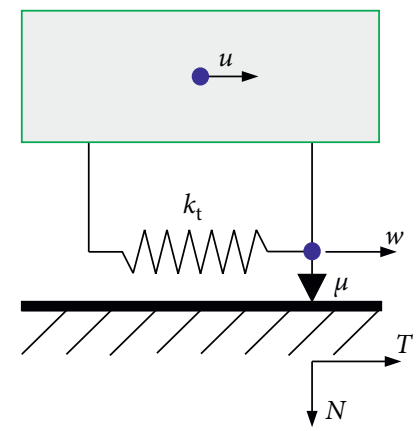

FIgURE 2: The structure diagram of the dry friction.

TABle 1: Model parameters of the coupled disk-beam system with the dovetail interface feature.

\begin{tabular}{lcc}
\hline Parameter & Disk & Beam \\
\hline Contact stiffness $k_{\mathrm{t}}: 8 \times 10^{6} \mathrm{~N} / \mathrm{m}$ & Density: $\rho_{\mathrm{D}} 7850 \mathrm{~kg} / \mathrm{m}^{3}$ & Density: $\rho_{\mathrm{b}} 7850 \mathrm{~kg} / \mathrm{m}^{3}$ \\
Friction coefficient: $\mu 0.3$ & Young's modulus: $E_{\mathrm{D}} 200 \mathrm{Gpa}$ & Young's modulus: $E_{\mathrm{b}} 200 \mathrm{GPa}$ \\
Beam number: $N_{\mathrm{b}} 6$ & Outer radius: $R_{\mathrm{D}} 0.35 \mathrm{~m}$ & Beam length: $L_{\mathrm{b}} 0.15 \mathrm{~m}$ \\
Tenon angle: $\gamma 60^{\circ}$ & Thickness: $h_{\mathrm{D}} 0.0275 \mathrm{~m}$ & Beam width: $b 0.06 \mathrm{~m}$ \\
Angle of contact surface: $\phi 30^{\circ}$ & Inner radius: $R_{\mathrm{s}} 0.025 \mathrm{~m}$ & Beam thickness: $h_{\mathrm{b}} 0.007 \mathrm{~m}$ \\
Angle of contact surface: $\eta 30^{\circ}$ & Poisson ratio: $v_{D} 0.3$ & Stagger angle: $\beta 30^{\circ}$ \\
\hline
\end{tabular}

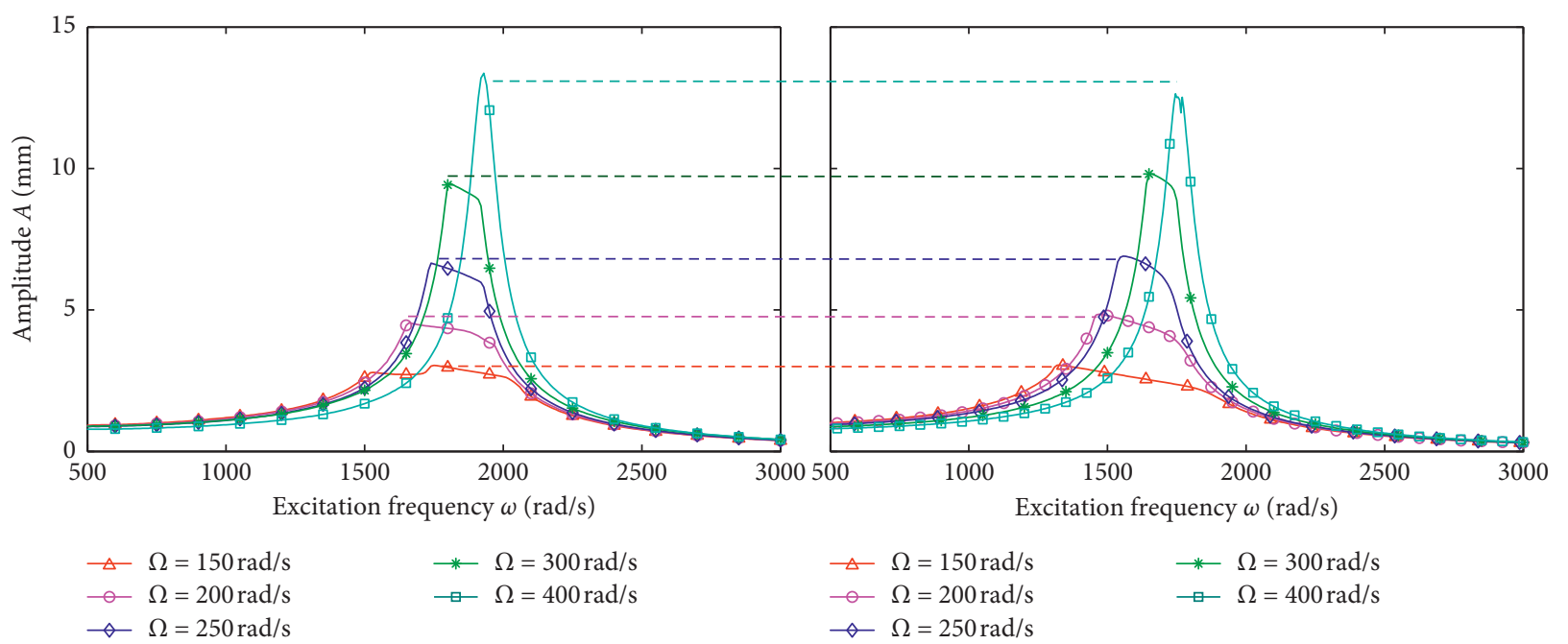

(a)

(b)

FIGURE 3: Variation of the beam's response curves versus rotational speed for $F=300 \mathrm{~N}$ : (a) the developed model and (b) the FE model.

By comparing the amplitude-frequency response curves of the different models in Figure 3, note that the errors between the two models mainly lie in the resonance amplitude of the rotating beam for $\Omega=300 \mathrm{rad} / \mathrm{s}$ and $\Omega=400 \mathrm{rad} / \mathrm{s}$; besides, there are also slight errors in the resonance frequencies. The main reason for these errors can be attributed to the difference in the modeling method. In the FE model, the continuum beam is divided into discrete finite elements for improving the calculation efficiency, replacing the continuous displacement field with the discrete displacement field. Besides, in the proposed model, a new mode function in Section 2.2 is developed to describe the boundary conditions of the beam with the dovetail interface feature. Consequently, the error of the newly derived mode function can also result in these differences. However, the difference in the response amplitude is not conspicuous, which points out that the amplitude-frequency responses obtained from the two models are in good agreement. Moreover, the present study mainly focuses on the mechanism analysis of the nonlinear coupling vibration of the disk-beam system. Thus, it can be considered that the mechanism model in the present study has sufficient accuracy and reliability.

\section{Numerical Results}

Table 1 illustrates the model parameters of the coupling system. Note that the flexible disk is deliberately elongated to magnify the influence of disk flexibility on the nonlinear dynamics of the coupling system. 

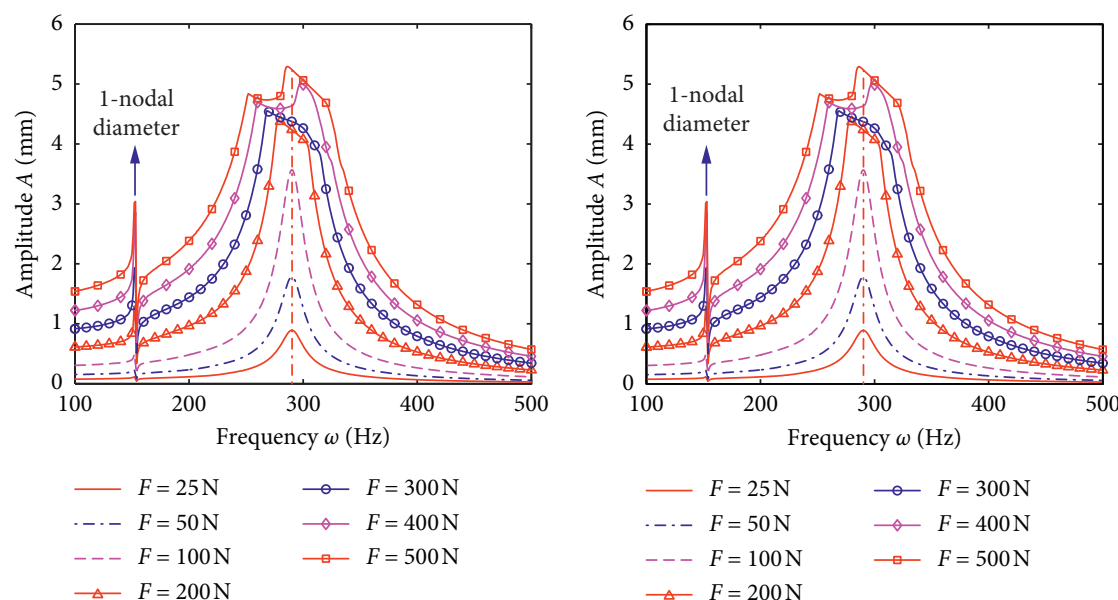

(b)
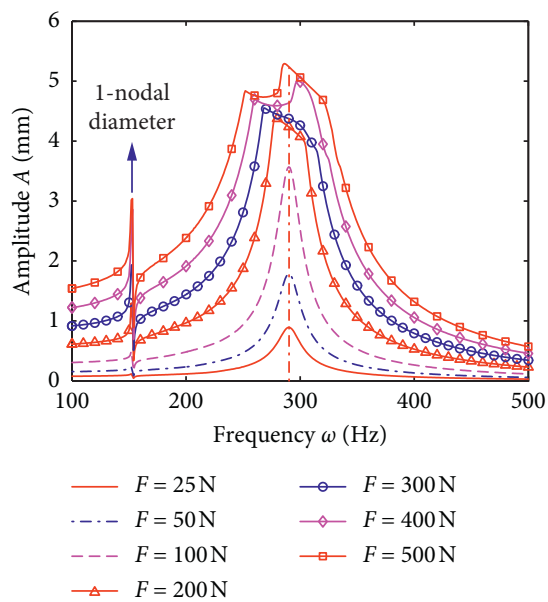

(d)
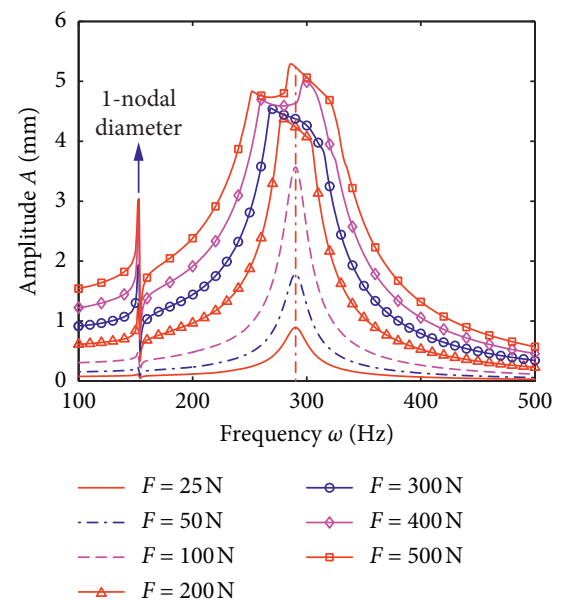

(e)
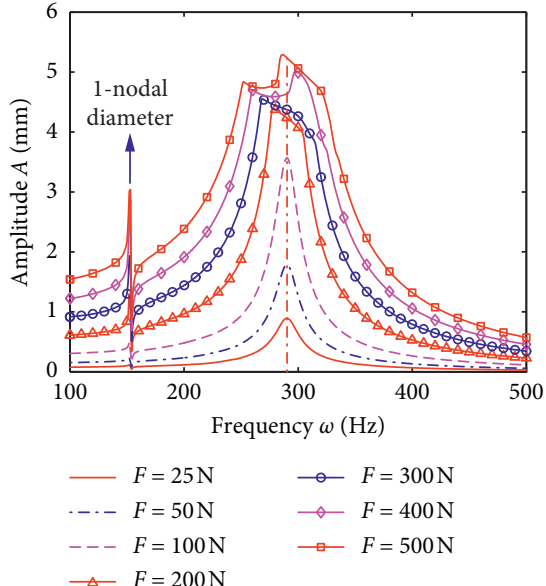

(c)

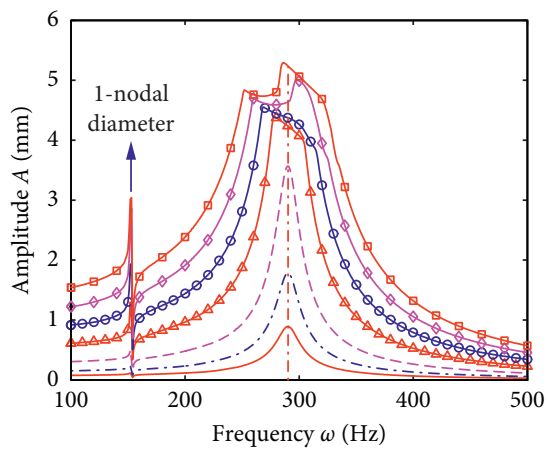

(f)

Figure 4: Amplitude-frequency response curves of beam 1 to beam 6 for different excitation levels: (a) beam 1, (b) beam 2, (c) beam 3, (d) beam 4, (e) beam 5, and (f) beam 6.

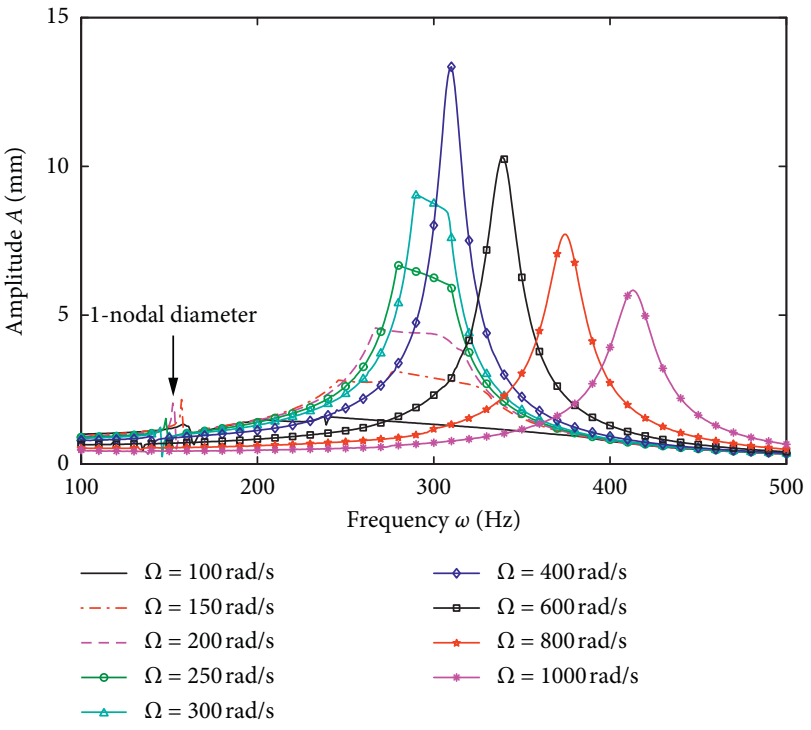

FIGURE 5: The amplitude-frequency response curves of beam 1 for different rotational speeds.
The amplitude-frequency response curves of beam 1 to beam 6 for $\Omega=200 \mathrm{rad} / \mathrm{s}$ are plotted in Figure 4. The results reveal that the nonlinear characteristics of beam 1 to beam 6 are identical to each other due to the cycle symmetry. Therefore, in the following study, the response of beam 1 is taken as an example to analyze the nonlinear characteristics of the disk-beam system. Besides, due to the coupling effect between disk transverse and beam bending, a slight resonance peak occurs at the frequency of the disk's 1-nodal diameter. Consequently, a coupling disk-beam model, considering the dry friction contact feature, is established in this paper. Furthermore, the displacement of the beam is significantly higher than that of the flexible disk, and this paper will mainly analyze the nonlinear characteristics of the beam. Besides, as depicted in Figure 4, in the case of low excitation amplitude, the contact DOFs are in sticking state. Therefore, the resonance peak is identical to the underlying linear system with bonded DOFs at the contact interface. When the excitation level is high enough, and the slipping state occurs between the DOFs in the contact interface, the resonance peaks gradually shift toward a lower frequency, corresponding to the case with frictionless interface case. 


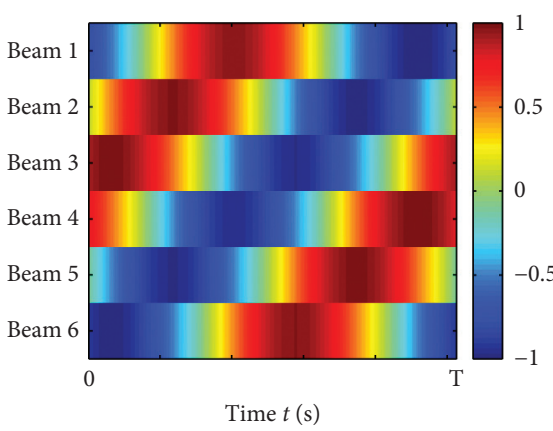

(a)

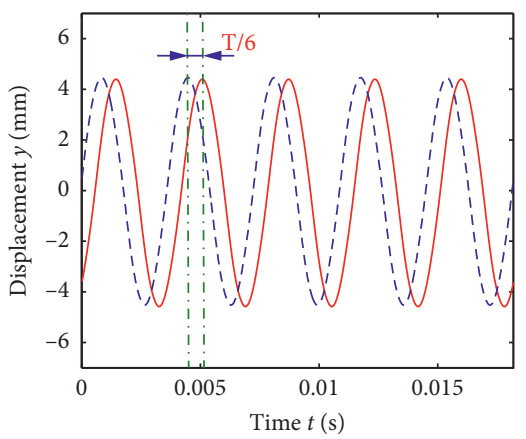

- Beam 1

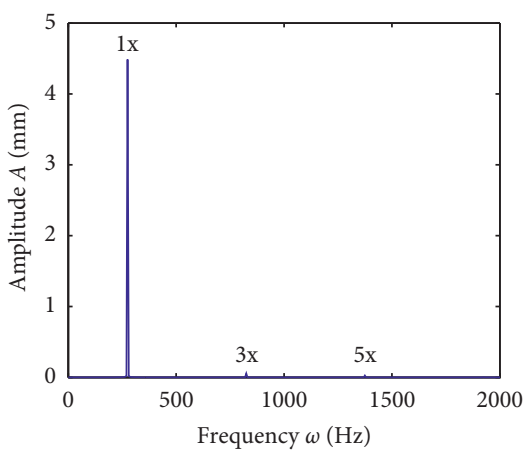

(b)

FIGURE 6: The response of beam tip for $\Omega=200 \mathrm{rad} / \mathrm{s}$ : (a) response of beam 1 to beam 6 , (b) response curve of beam 1 and 2 , and (c) spectrum plot of beam 1 .

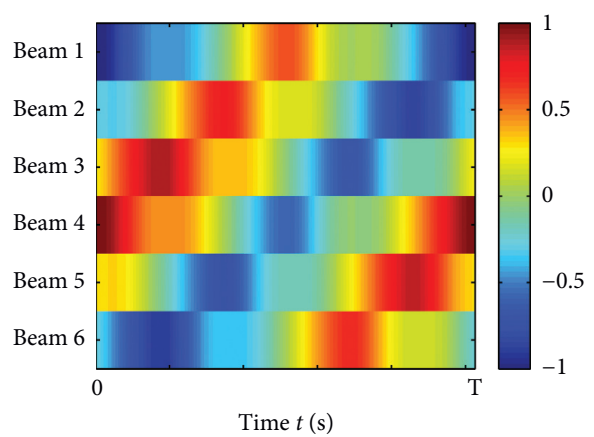

(a)

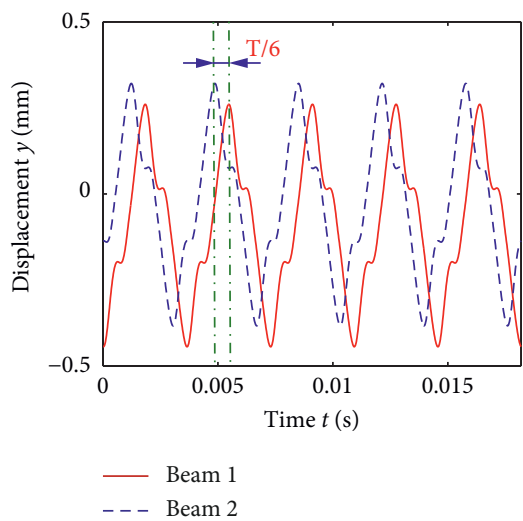

(b)

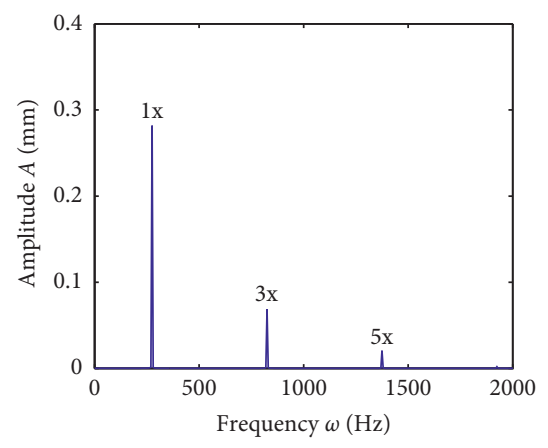

(c)

Figure 7: The response of beam root for $\Omega=200 \mathrm{rad} / \mathrm{s}$ : (a) response of beam 1 to beam 6 , (b) response curve of beam 1 and 2, and (c) spectrum plot of beam 1 .

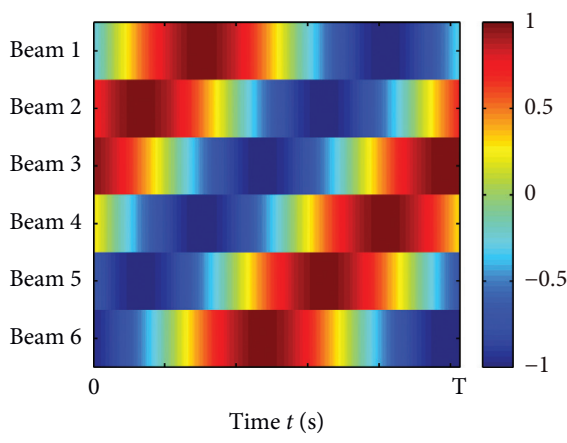

(a)

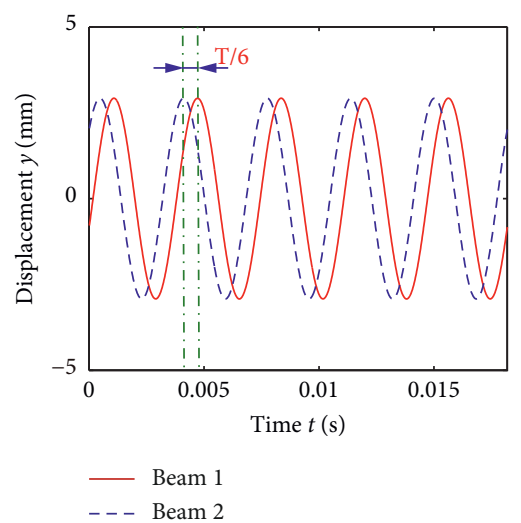

(b)

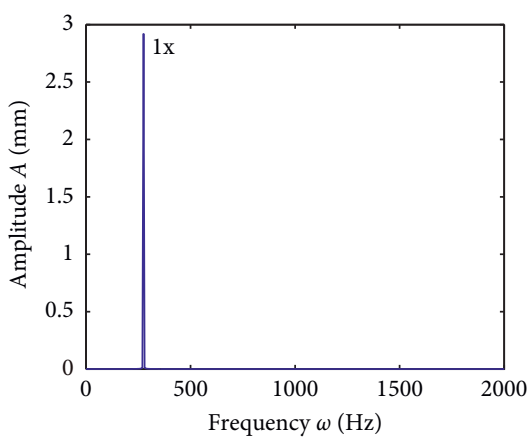

(c)

FIGURE 8: The response of beam tip for $\Omega=400 \mathrm{rad} / \mathrm{s}$ : (a) response of beam 1 to beam 6, (b) response curve of beam 1 and 2, and (c) spectrum plot of beam 1 .

According to [29], this phenomenon is commonly referred to as a softening nonlinearity due to the friction between the contact DOFs.
Finally, the computation of numerical results in Figure 4 shows that this continuum model can be used for nonlinear vibration analysis efficiently with finite DOFs, compared 


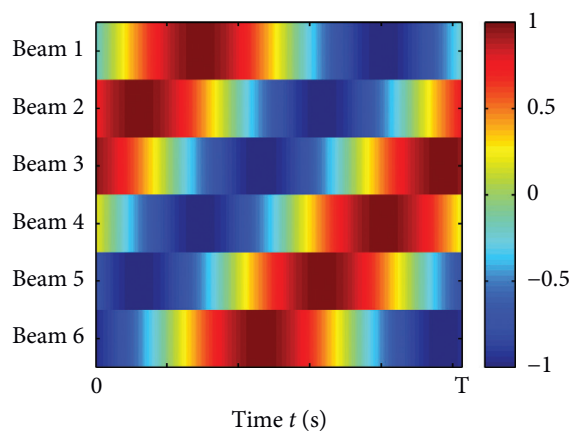

(a)

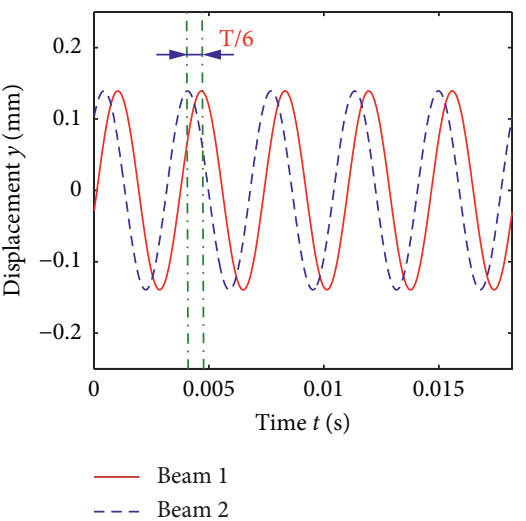

(b)

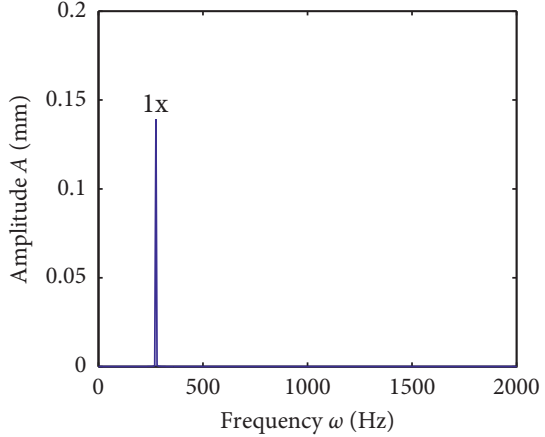

(c)

FIGURE 9: The response of beam root for $\Omega=400 \mathrm{rad} / \mathrm{s}$ : (a) response of beam 1 to beam 6, (b) response curve of beam 1 and, and (c) spectrum plot of beam 1 .

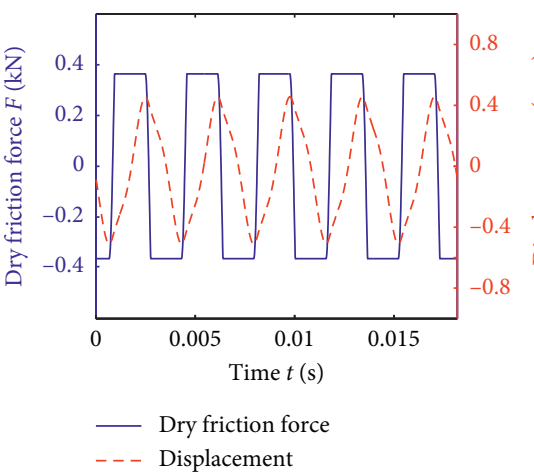

(a)

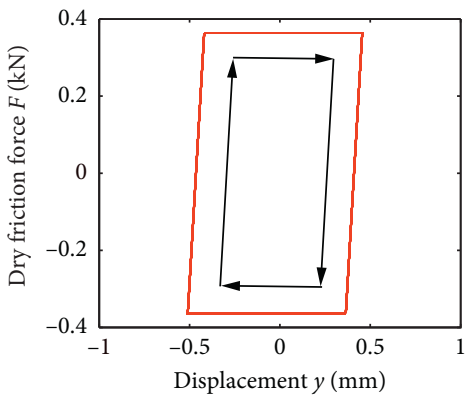

(d)

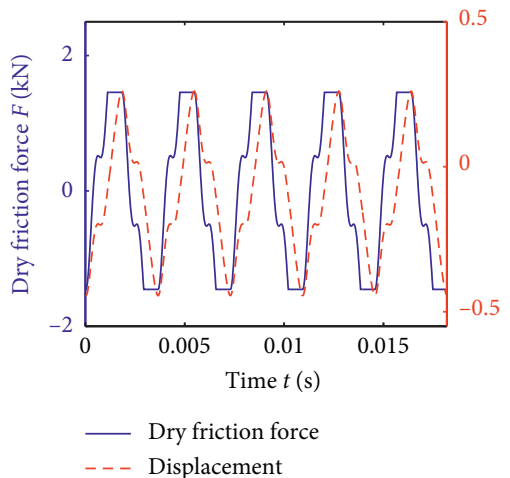

(b)

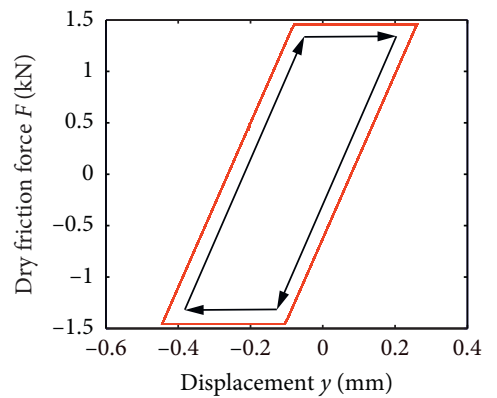

(e)

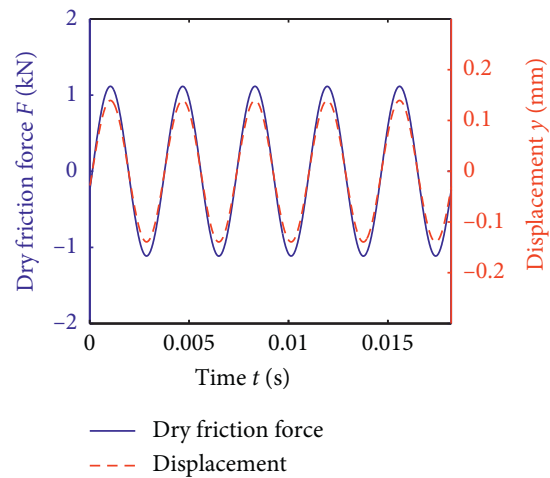

(c)

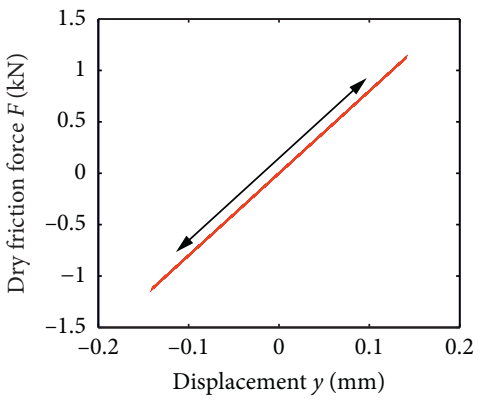

(f)

FIGURE 10: Dry friction force for different rotational speeds: $(a-c)$ represent the dry friction force curve and the response curve, and (d-f) describe the hysteresis loop.

with the finite element model. And the validation section also indicates that this continuum model is also accurate for the mechanism analysis. Besides, the amplitude-frequency response curves in Figure 4 exhibit that only 1-nodal diameter mode of flexible disk plays a conspicuous role in the nonlinear coupling vibration. Therefore, in the following analysis, we can only consider the flexible disk's 1-nodal diameter mode, which can further improve the computation efficiency. Consequently, compared to the FE reduction model, we can only choose the mode that we are interested in to calculate and study easily. It means that the derived model in the present study has more flexibility and computation efficiency. As for FEM, it is very suitable for solving practical problems in engineering. However, FEM lacks computation efficiency and flexibility in a series of aspects, such as modifying geometric parameters, although the order reduction method is employed. In particular, there exist coupling vibration problems among the multiple subcomponents in the system, such as the problem in $[15,31]$. Consequently, for discussing the mechanism simply and 


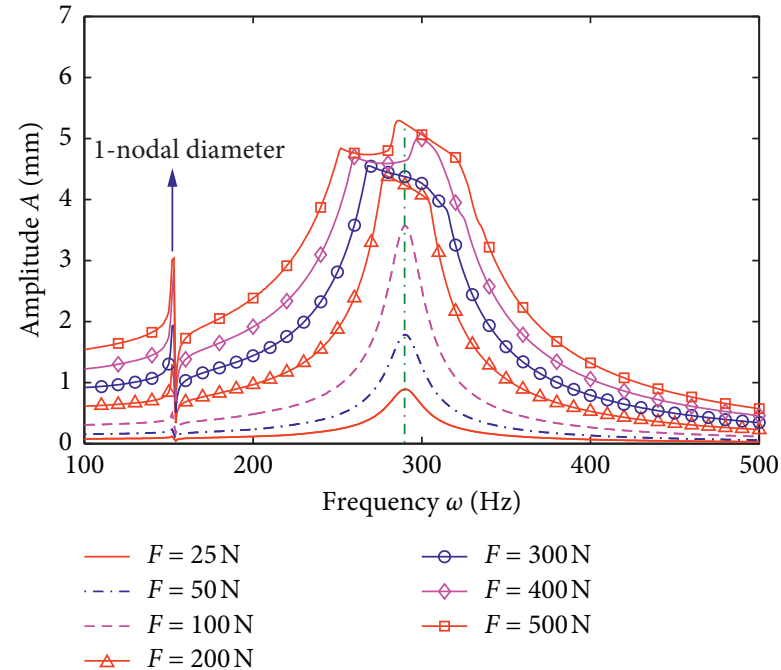

(a)

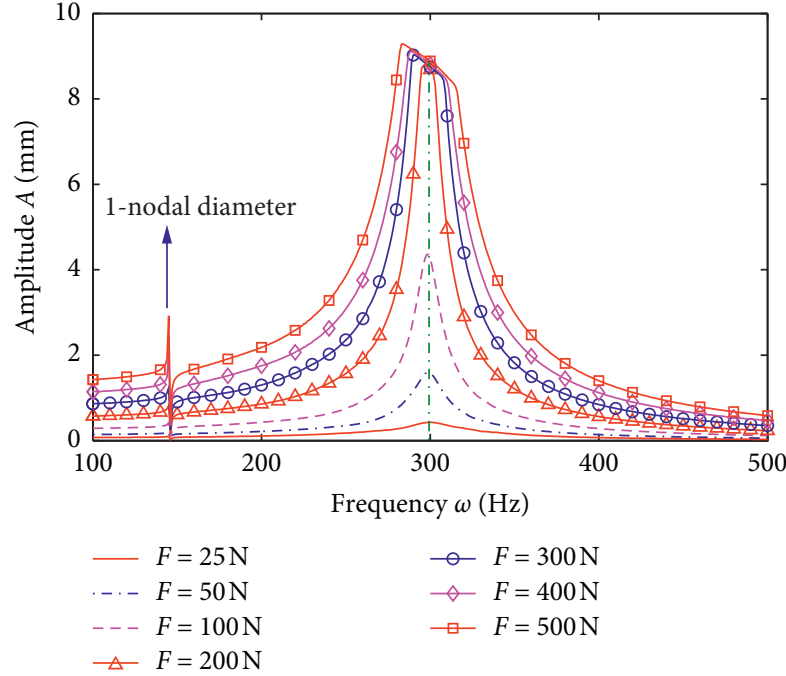

(b)

Figure 11: The amplitude-frequency response curve of beam 1 for different excitation levels $F$ : (a) $\Omega=200 \mathrm{rad} / \mathrm{s}$ and (b) $\Omega=300 \mathrm{rad} / \mathrm{s}$.

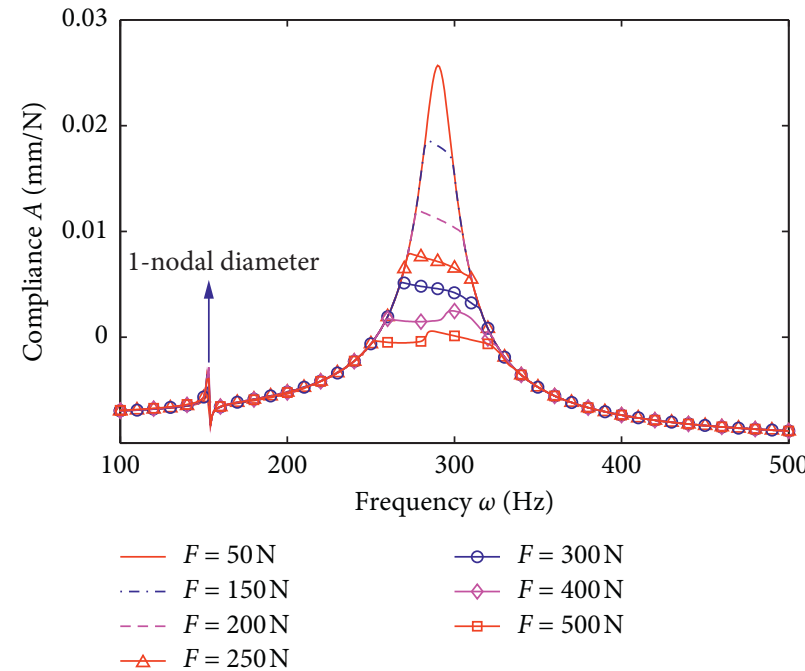

(a)

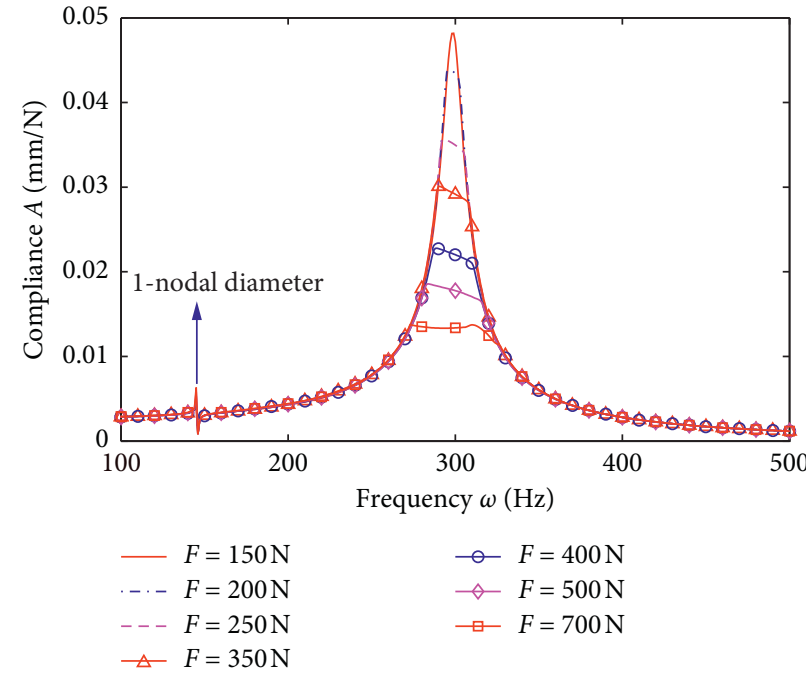

(b)

Figure 12: The compliance of beam 1 for different excitation levels $F:$ (a) $\Omega=200 \mathrm{rad} / \mathrm{s}$ and (b) $\Omega=300 \mathrm{rad} / \mathrm{s}$.

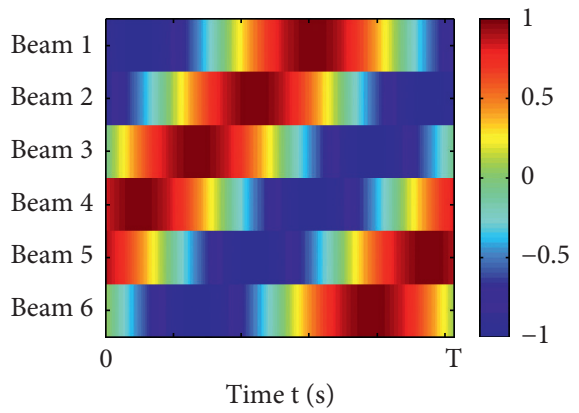

Time t (s)

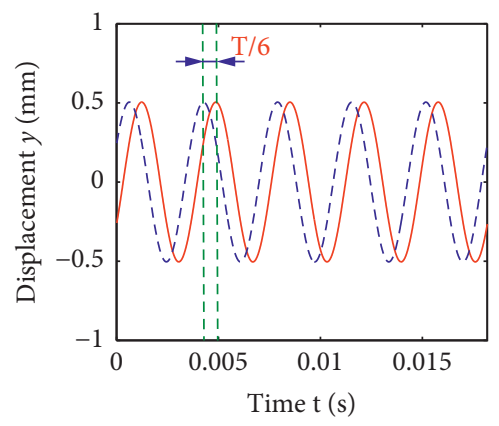

- Beam 1

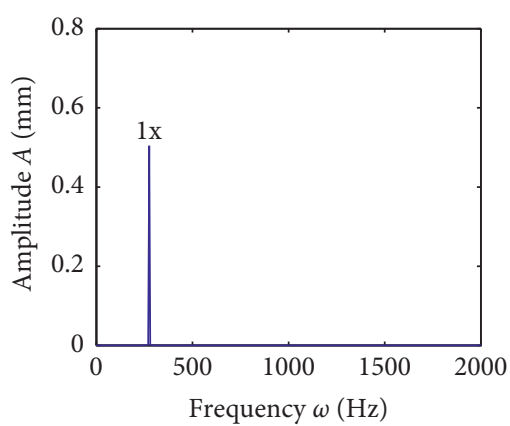

(c)

(a)

(b)

Figure 13: The response of beam tip with respect to case $1(\Omega=200 \mathrm{rad} / \mathrm{s}, F=25 \mathrm{~N}, \omega=300 \mathrm{~Hz})$ : (a) response of beam 1 to beam 6 , (b) response curve of beams 1 and 2, and (c) spectrum plot of beam 1 . 


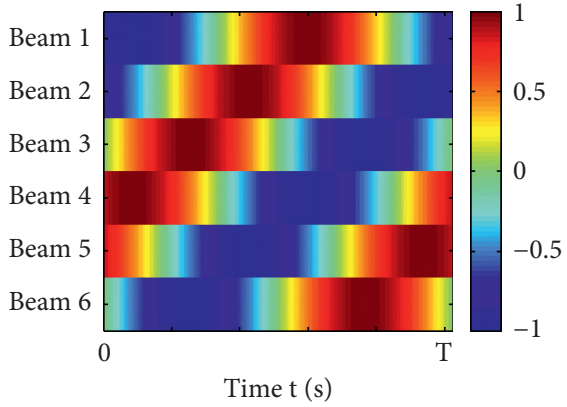

Time t (s)

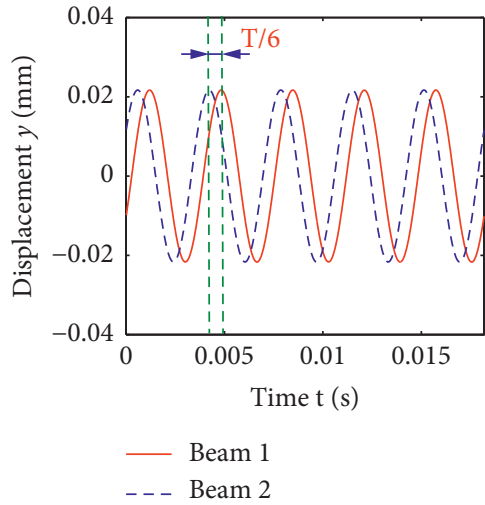

(b)

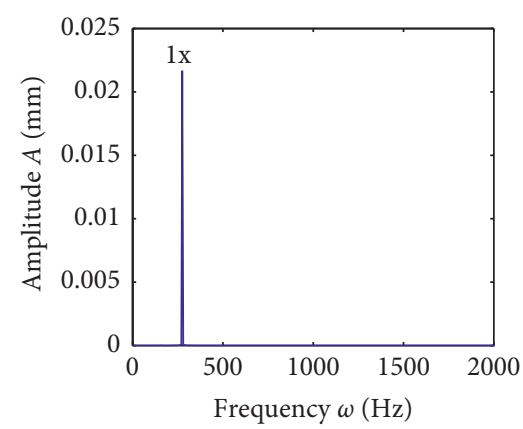

(c)

Figure 14: The response of beam root with respect to case $1(\Omega=200 \mathrm{rad} / \mathrm{s}, F=25 \mathrm{~N}, \omega=300 \mathrm{~Hz})$ : (a) response of beam 1 to beam 6 , (b) response curve of beams 1 and 2, and (c) spectrum plot of beam 1.

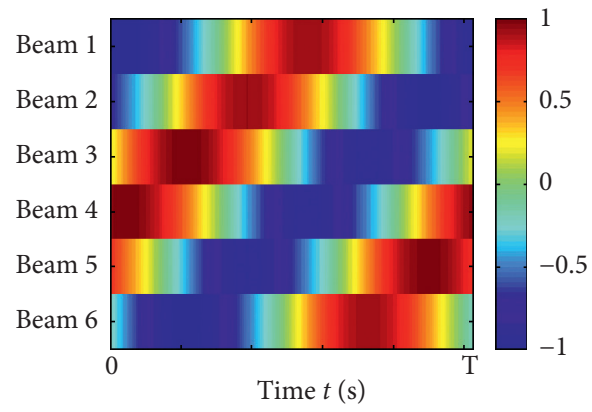

(a)

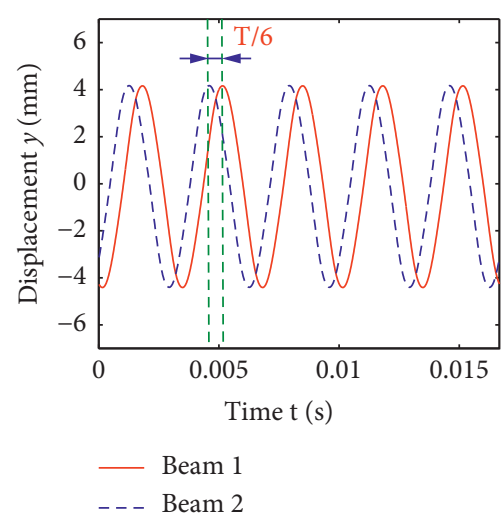

(b)

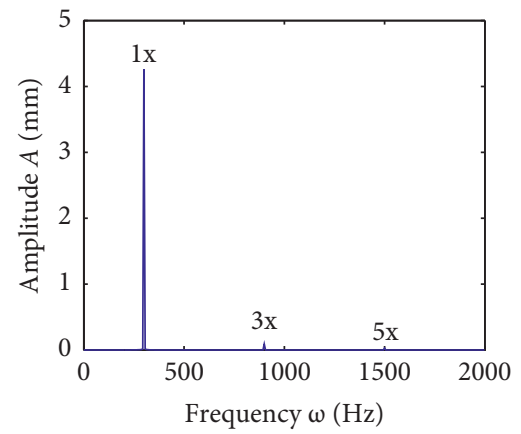

(c)

Figure 15: The response of beam tip with respect to case $2(\Omega=200 \mathrm{rad} / \mathrm{s}, F=300 \mathrm{~N}, \omega=300 \mathrm{~Hz}$ ): (a) response of beam 1 to beam 6 , (b) response curve of beams 1 and 2, and (c) spectrum plot of beam 1.

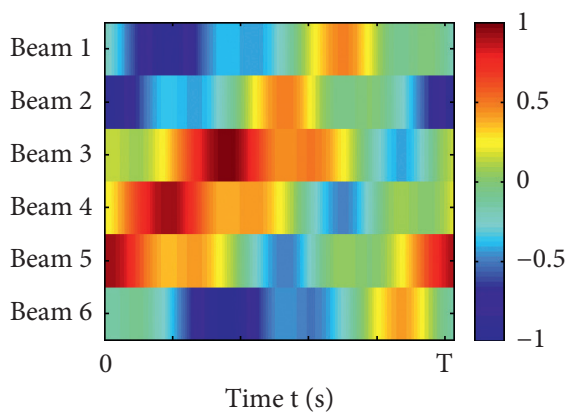

(a)

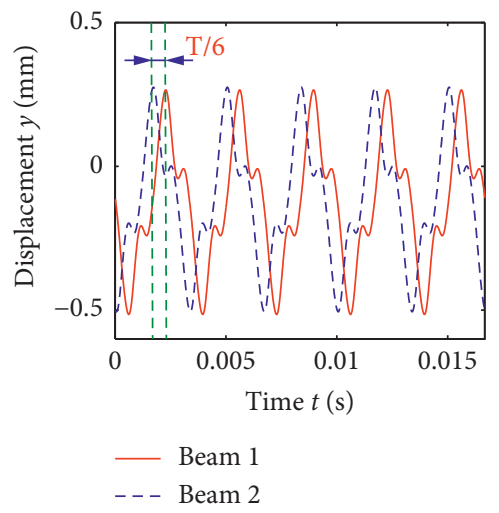

(b)

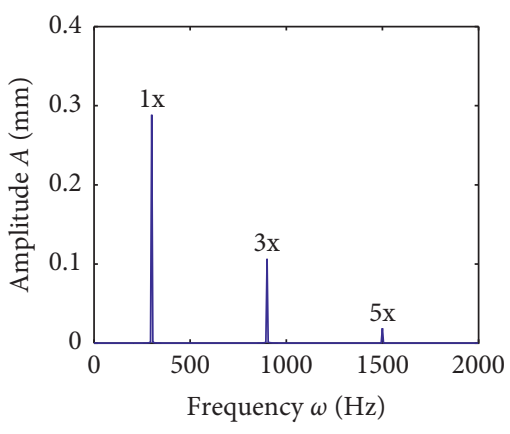

(c)

FIgURE 16: The response of beam root with respect to case $2(\Omega=200 \mathrm{rad} / \mathrm{s}, F=300 \mathrm{~N}, \omega=300 \mathrm{~Hz})$ : (a) response of beam 1 to beam 6 , (b) response curve of beams 1 and 2, and (c) spectrum plot of beam 1.

efficiently, the derived continuum is a very effective choice. Therefore, FEM in this paper is only used to validate the continuum model and the reliability of the analysis results.
5.1. The Nonlinear Characteristic for Different Rotational Speeds. Beam with loosely assembled dovetail attachment is a kind of loose structure. During the operation of the unit, 


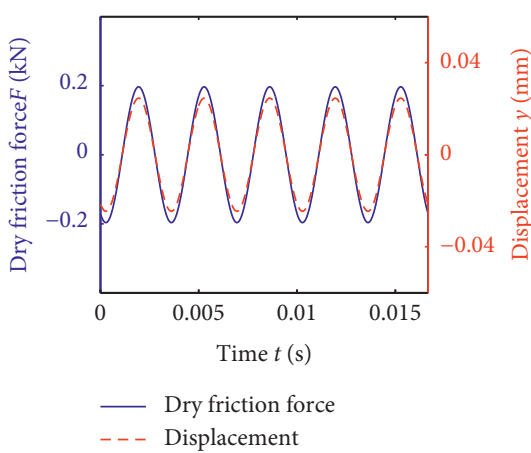

(a)

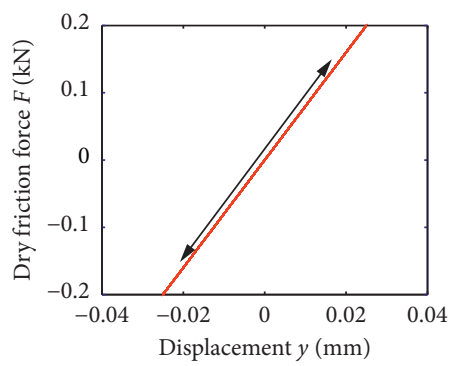

(d)

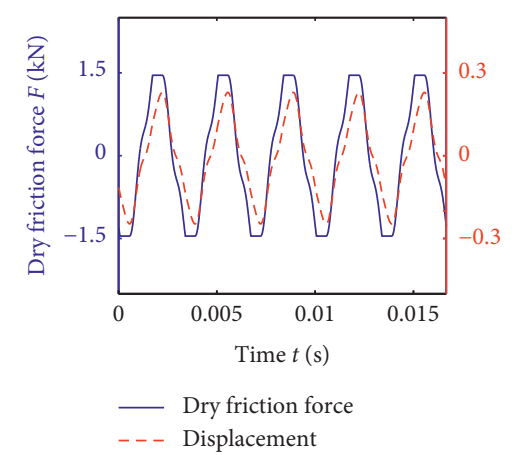

(b)

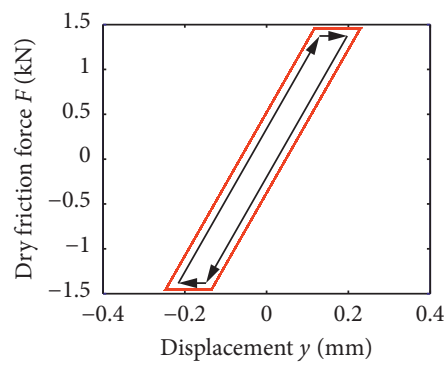

(e)

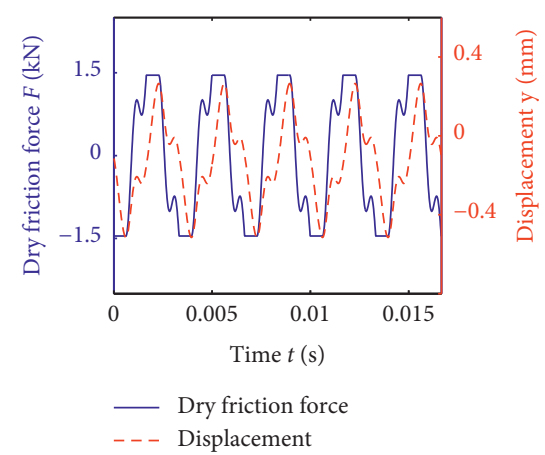

(c)

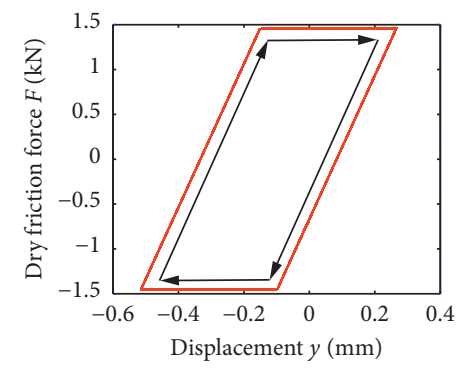

(f)

FIGURE 17: Dry friction force with respect to cases 1 3: (a-c) represent the dry friction force curve and the response curve; (d-f) describe the hysteresis loop.

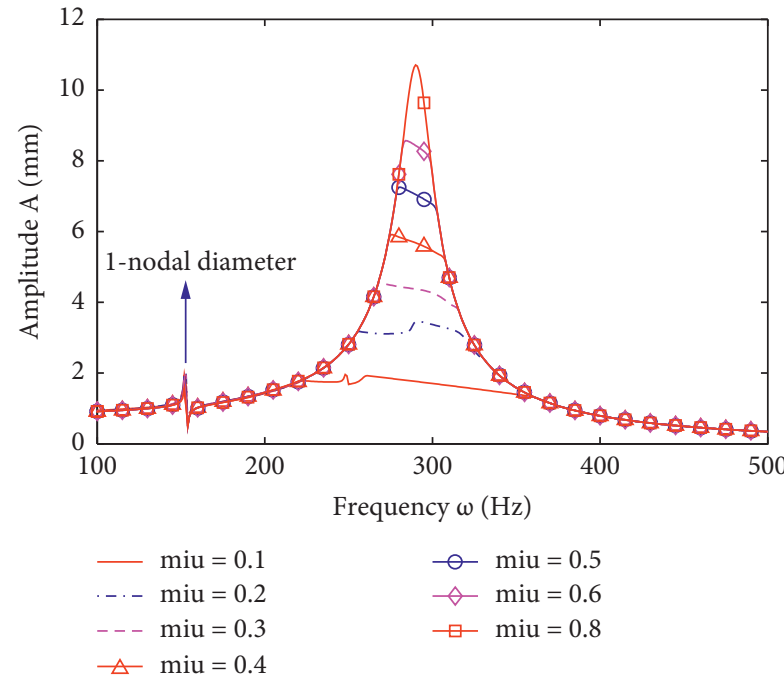

(a)

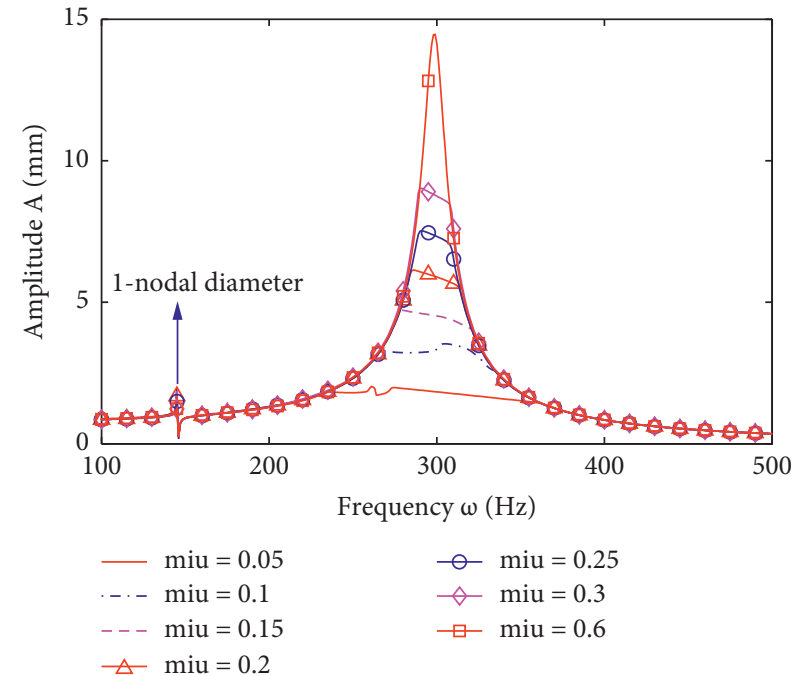

(b)

Figure 18: The amplitude-frequency response curves of beam 1 for different friction coefficients: (a) $\Omega=200 \mathrm{rad} / \mathrm{s}$ and (b) $\Omega=300 \mathrm{rad} / \mathrm{s}$.

beam root and disk form the contact surface under the influence of centrifugal force, inducing a complex system with nonlinear boundary conditions. In this paper, the contact feature between the beam root and disk is considered as a dry friction model. And the response of a rotating diskbeam system is calculated to investigate the nonlinear characteristics. The contact between the beam and disk is generated by centrifugal force, which is related to rotational speed and beam mass. In the process of the unit's starting and stopping, the centrifugal force of the beam will vary with rotational speed. This variation will greatly affect the dry friction force between the beam root and disk.

The amplitude-frequency response curves of beam 1 for different rotational speeds are given in Figure 5 when the excitation level is $F=300 \mathrm{~N}$. The amplitude-frequency curves of the beam show a certain softening nonlinearity at a low rotational speed. However, the nonlinear phenomenon disappears at a higher rotational speed. Besides, the resonance 


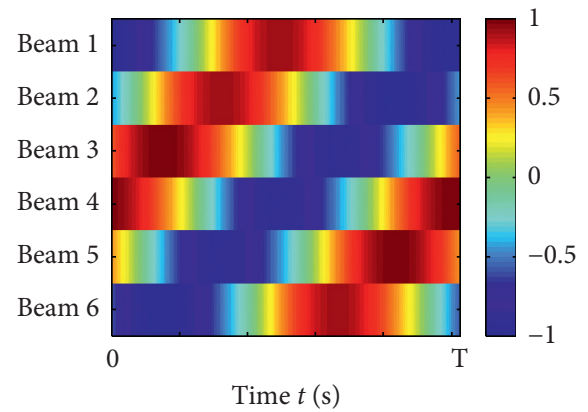

(a)

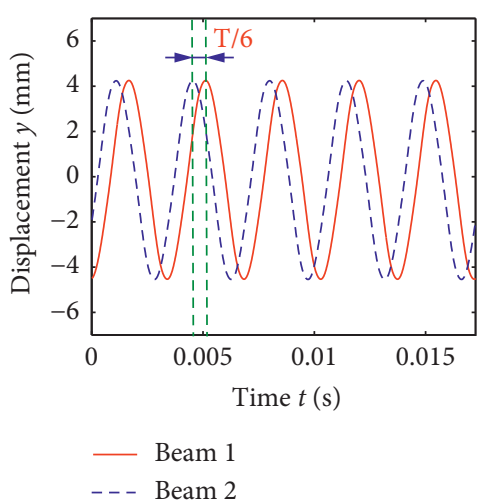

(b)

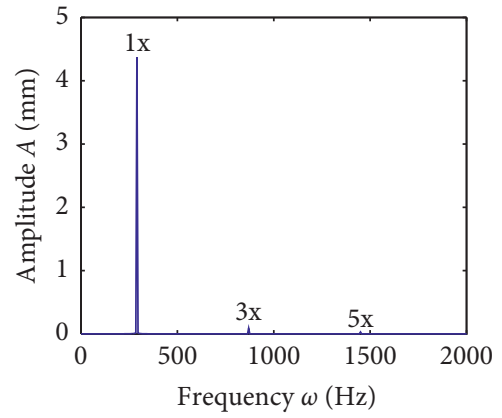

(c)

FIGURE 19: The response of beam tip for $\mu=0.3$ : (a) response of beam 1 to beam 6, (b) response curve of beams 1 and 2, and (c) spectrum plot of beam 1 .

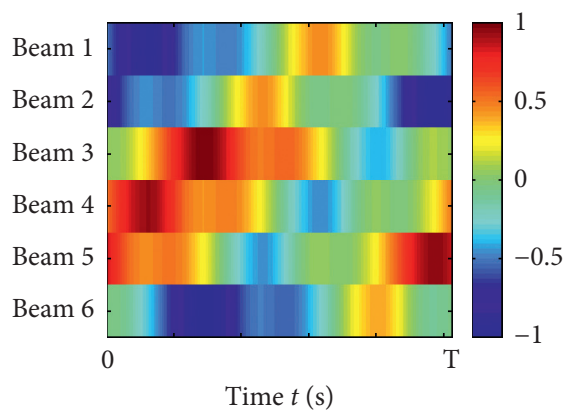

(a)

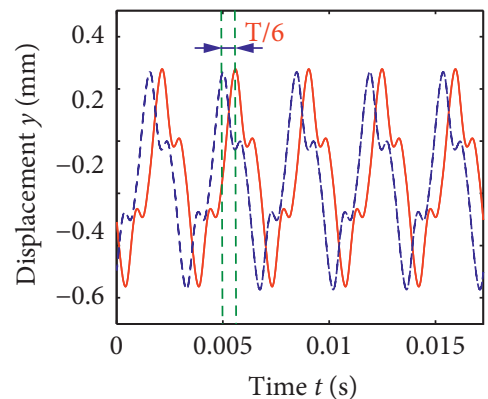

- Beam 1

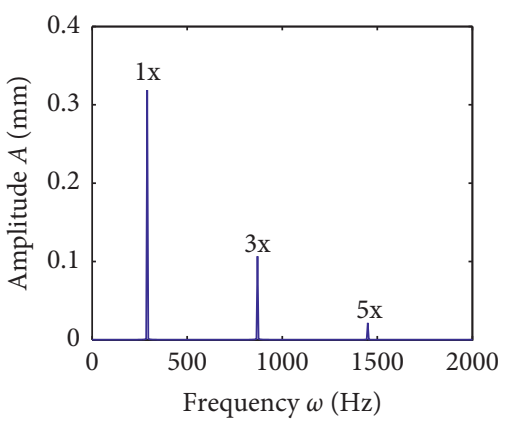

(c)

FiguRE 20: The response of beam root for $\mu=0.3$ : (a) response of beam 1 to beam 6 , (b) response curve of beams 1 and 2, and (c) spectrum plot of beam 1 .

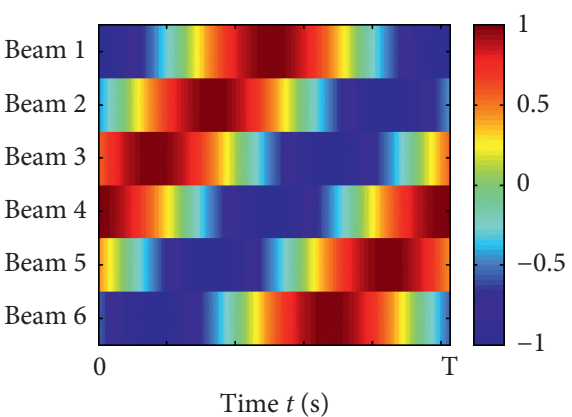

(a)

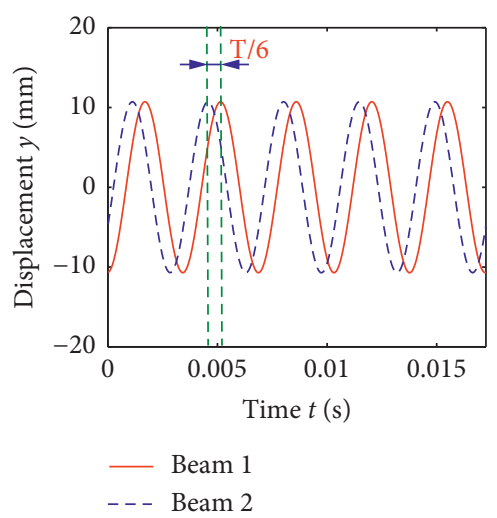

(b)

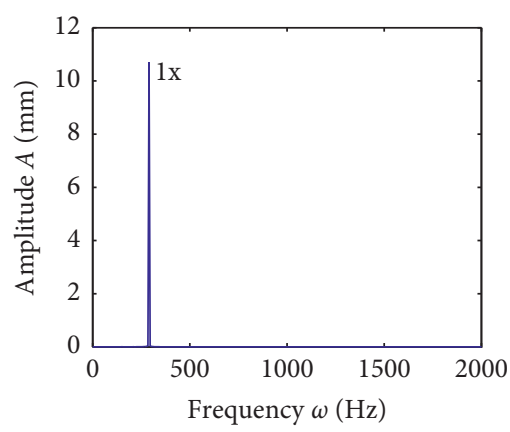

(c)

FIGURE 21: The response of beam tip for $\mu=0.8$ : (a) response of beam 1 to beam 6 , (b) response curve of beams 1 and 2, and (c) spectrum plot of beam 1.

frequency gradually shifts toward the right for a higher rotational speed case. After comparing the resonance amplitude of the blade bending under different rotational speeds, it can be noted that it firstly increases and then decreases with rotational speed. The results show that the beam's centrifugal force increases with rotational speed, so the positive pressure of contact 


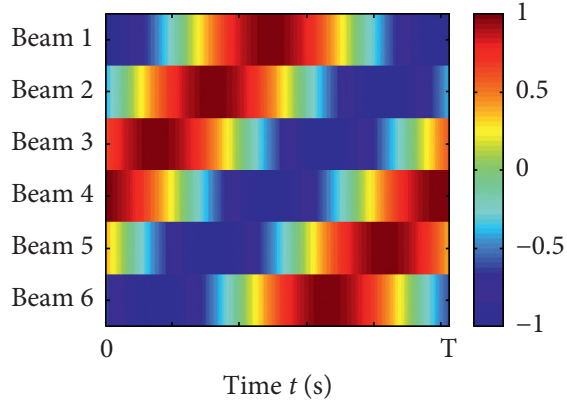

Time $t(\mathrm{~s})$

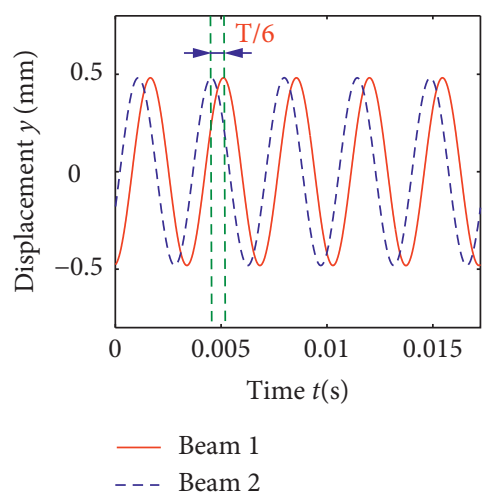

(b)

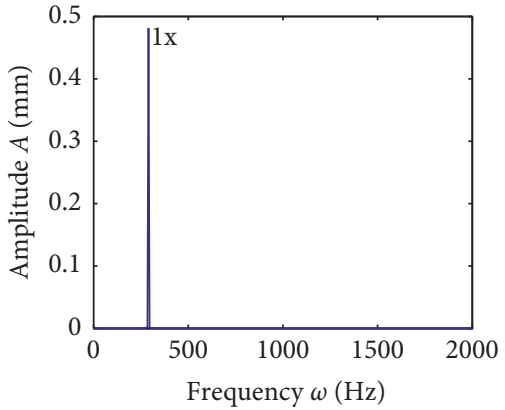

(c)

FIgURE 22: The response of beam root for $\mu=0.8$ : (a) response of beam 1 to 6 , (b) response curve of beams 1 and 2, and (c) spectrum plot of beam 1 .

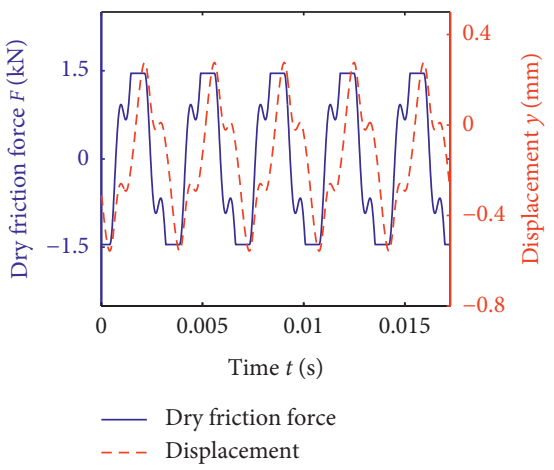

(a)

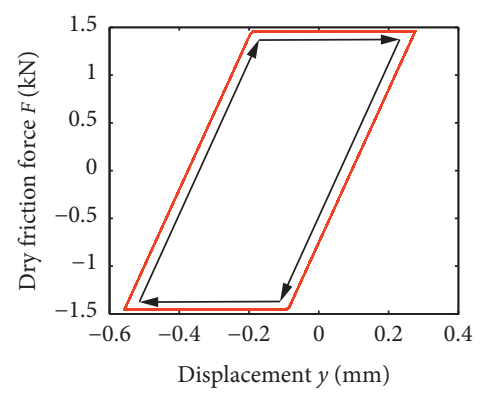

(d)

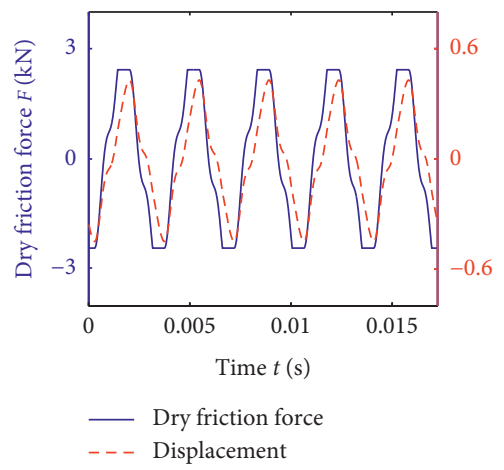

(b)

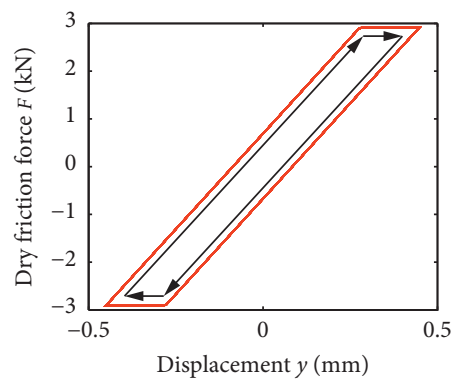

(e)

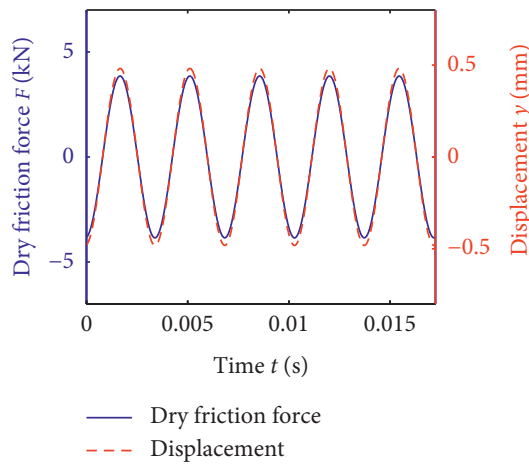

(c)

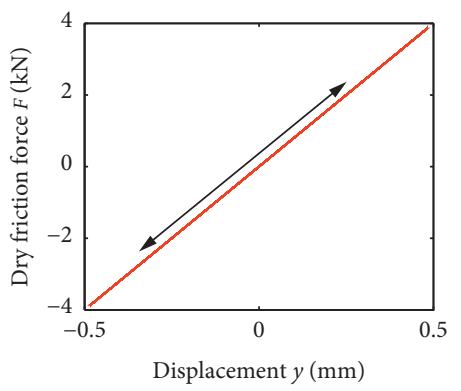

(f)

FIgURE 23: Dry friction force for different friction coefficients: $(a-c)$ represent the dry friction force curve and the response curve; $(d-f)$ describe the hysteresis loop.

surface between the beam root and disk increases continuously. The increasing contact pressure enhances the restraint of the contact surface on the beam root and makes the beam root gradually shifts toward the full-sticking state. Consequently, the slipping phenomenon of contact DOFs gradually disappears as the increase of rotation speed when the excitation level $F$ keeps in constant.

Further analysis of the influence of the rotational speed on nonlinear characteristics is given in Figures 6-9. The time series of the response of beam 1 to beam 6 at tips and roots for different rotational speeds are provided. A special graph is used to plot the response of beam 1 to beam 6 in the same graph, as shown in Figure 6(a). In the case of $200 \mathrm{rad} / \mathrm{s}$ and $400 \mathrm{rad} / \mathrm{s}$, the forced response of the beam is given in Figures 6-9 for $\omega=275 \mathrm{~Hz}$ and $F=300 \mathrm{~N}$, respectively. Figures $6(\mathrm{a})$ and $7(\mathrm{a})$ illustrate the response of beam 1 to beam 6 at tips and roots for $\Omega=200 \mathrm{rad} / \mathrm{s}$. It shows that the response of the rotating beams exhibits the traveling wave propagating in the same direction. This points out that the response of beam 1 to beam 6 is in good agreement. However, the phase lag, caused by the travelling excitation, cannot be seen clearly on the time series due to the activation of dry friction force. For analyzing the response characteristics in detail, the response curves and spectrum plots of 
beam 1 at tip and root are illustrated in Figures 6(b), 6(c), $7(\mathrm{~b})$, and $7(\mathrm{c})$, respectively. The results show that the response curve of beam 1, especially that of beam root, exhibits obvious nonlinearity at $\Omega=200 \mathrm{rad} / \mathrm{s}$. These response results point out that the slipping of dry friction occurs, which plays an important role in dissipating vibration energy of the beam at this time.

The time series of the response of beam 1 to beam 6 for $\Omega=400 \mathrm{rad} / \mathrm{s}$ is shown in Figures 8 and 9. These time series of the response of beam 1 to beam 6 with a characteristic diagonal pattern result in the phase lag that can be seen clearly. The response curve of beam 1 is a linear harmonic wave, and there is only $1 \mathrm{x}$ in the spectrum plot. Besides, the vibration amplitude of beam 1 at the tip and root increases with respect to the case of $\Omega=200 \mathrm{rad} / \mathrm{s}$. From these phenomena, it can be concluded that no slipping occurs, and dry friction does not dissipate energy anymore. The result that the increasing positive pressure on the contact surface that makes the occurrence of slipping more difficult can be interpreted. As a consequence, the beam system gradually shifts toward a system with the full-stick interface at a high rotational speed.

An analysis of the influence of rotational speed on dry friction force is illustrated in Figure 10. A dual $y$-axis is adopted in Figures 10(a)-10(c) to plot the time series of dry friction force and response curve of beam root, respectively. Then, the hysteresis loops of dry friction force are illustrated in Figure $10(\mathrm{~d})-10(\mathrm{f})$ when the rotational speed is $200 \mathrm{rad} / \mathrm{s}$, $250 \mathrm{rad} / \mathrm{s}$, and $400 \mathrm{rad} / \mathrm{s}$, respectively. For $\Omega=200 \mathrm{rad} / \mathrm{s}$ and $\Omega=250 \mathrm{rad} / \mathrm{s}$, the force curves of dry friction exhibit obvious slipping phenomenon and sticking state, respectively. While the contact DOF keeps in sticking state, the contact force keeps in constant. The unchanged dry friction force will increase significantly with rotational speed. In the case of $\Omega=400 \mathrm{rad} / \mathrm{s}$, the curves of contact force and beam response will gradually shift toward a harmonic wave. Corresponding hysteresis loop of contact force evolves from a closed parallelogram to a straight line. These phenomena indicate that dry friction force transfers from nonlinear force to linear force at a higher rotational speed. The area of the hysteresis loop represents the energy dissipated by dry friction. The results reveal that dry friction does not dissipate energy anymore at a high rotational speed.

\subsection{The Nonlinear Characteristics for Different Excitation} Levels. The excitation level can affect the response characteristics of the coupling system significantly. As a consequence, the nonlinear characteristics of the coupled system for different excitation levels are investigated. The amplitude-frequency response curves of beam 1 are first displayed in Figure 11 for $\Omega=200 \mathrm{rad} / \mathrm{s}$ and $\Omega=300 \mathrm{rad} / \mathrm{s}$, respectively. The results show that the resonance frequency keeps in constant and equal to that of the linear system with bonded DOFs at low excitation amplitude. The phenomenon that the beam root is in a stationary sticking state in such a case can be interpreted. However, the nonlinearity is activated when the excitation level is high enough, indicating that the slipping state happens on the contact surface between the beam root and disk. And the resonance frequency gradually shifts toward the lower frequency, corresponding to the linear case. The results reveal that the dry friction contact is commonly referred to as a softening nonlinearity. Besides, the resonance amplitude increases with the excitation level, while a more significant slipping phenomenon occurs. The phenomenon indicates that dry friction dissipates the vibration energy of the beam and decreases the vibration amplitude of the beam. In addition to the variation of vibration amplitude, the frequency range of the slipping phenomenon also obviously increases with the excitation level. Furthermore, a high resonance amplitude appears at the frequency of the disk's 1-nodal diameter for a higher excitation level. The phenomenon is more obvious with the increase of rotational speed. These point out that disk flexibility has a conspicuous impact on the beam response at higher excitation levels.

Compliance is further used to investigate the nonlinearity of the coupling system. The compliances of beam response at $\Omega=200 \mathrm{rad} / \mathrm{s}$ and $\Omega=300 \mathrm{rad} / \mathrm{s}$ are illustrated in Figure 12. For obtaining the compliance of response, the amplitude-frequency curves of beam tip are computed for different excitation levels. The compliance for different excitation levels shows that there is no conspicuous nonlinearity for low excitation level, while the nonlinearity is gradually conspicuous for higher excitation level. This indicates that the nonlinearity is activated as the excitation level increases.

Further analysis of the effects of excitation level on nonlinear characteristics of the system is as follows. The time series of the response of beam 1 to beam 6 are calculated, and the spectrum plots of beam 1 are also computed to express the response characteristics of the rotating beams clearly. The response curves and spectrum plots of the beam are illustrated in Figures 13-14 for case $1(\Omega=200 \mathrm{rad} / \mathrm{s}$, $F=25 \mathrm{~N}, \omega=300 \mathrm{~Hz}$ ). In Figures $13(\mathrm{a})$ and $14(\mathrm{a})$, the response curves of beam 1 to beam 6 are shown for $t \in[0, T]$, respectively. The results indicate that the response of beam 1 to beam 6 is a traveling wave propagating in the same direction. The characteristic diagonal pattern in the traveling wave indicates that the response of beam 1 to beam 6 is in good agreement. And the phase lag in Figures 13(a) and $14(\mathrm{a})$, which varies from 0 to $2 \pi$, can be seen clearly. Figures 13(b) and 14(b) are the response curves of beam 1 at tip and root, respectively. The time series of the response of beams 1 and 2 are linear with a clear phase lag. Besides, there is only $1 \mathrm{x}$ in the spectrum plot, indicating that the beam root is under simple harmonic vibration. These phenomena point out that the beam is in a stationary sticking state, and the slipping phenomenon of dry friction does not occur. These show that dry friction does not dissipate energy at all.

The response curves and spectrum plots of the rotating beam are shown in Figures 15 and 16 for case $2(\Omega=200 \mathrm{rad} /$ s, $F=300 \mathrm{~N}, \omega=300 \mathrm{~Hz}$ ). In Figures 15(a) and 16(a), the time series of the response of beam 1 to beam 6 are plotted for $t \epsilon$ $[0, T]$, respectively. The traveling waves in Figure 16(a) are not with a characteristic diagonal pattern and result in the fact that the phase lag is not so clear. This is due to the nonlinearity of the dry friction force. However, the time 
series of the response of beams 1 and 2 in Figures 15(b) and 16(b) show that there still exists a phase lag between different beam responses. The time series of responses at the root of beams 1 and 2 exhibit conspicuous nonlinear characteristics, and $1 \mathrm{x}, 3 \mathrm{x}$, and $5 \mathrm{x}$ appear in the spectrum plot. These results indicate that the slipping phenomenon occurs, and dry friction dissipates vibration energy. The unclear phase lags between beam 1 and beam 6 reveal that the slipping state of dry friction does not affect the phase of the traveling wave.

Figure 17 illustrates the influence of the excitation level on dry friction force. A dual $y$-axis is adopted in Figures 17(a)-17(b) to plot the time series of contact friction force and response curve of beam root, respectively. Then, the hysteresis loops of dry friction force are plotted in Figures $17(\mathrm{~d})-17(\mathrm{f})$ for case $1(\Omega=200 \mathrm{rad} / \mathrm{s}, F=25 \mathrm{~N}$, $\omega=300 \mathrm{~Hz})$, case $2(\Omega=200 \mathrm{rad} / \mathrm{s}, F=200 \mathrm{~N}, \omega=300 \mathrm{~Hz})$, and case $3(\Omega=200 \mathrm{rad} / \mathrm{s}, F=300 \mathrm{~N}, \omega=300 \mathrm{~Hz})$, respectively. Note that, for low excitation level, the time series of contact force and the response of beam root present a harmonic wave, and the hysteresis loop exhibits a straight line. Since beam root keeps in sticking state at low excitation level, the slipping phenomenon does not occur, and dry friction does not dissipate any vibration energy. As the excitation level increases, the nonlinear characteristics occur in the time series of friction force and beam response. While the contact force reaches the maximum value, it will keep constant for a period. However, the time of dry friction force at maximum value will be affected by excitation amplitude. Moreover, the hysteresis loop of the contact force exhibits a closed parallelogram. The corresponding area of the parallelogram increases gradually with the excitation level. This points out that the energy dissipated by dry friction also increases gradually. However, the resonance amplitude still gradually increases, although the energy dissipated by dry friction force increases for the higher excitation level.

\subsection{The Nonlinear Characteristics for the Different Friction} Coefficients. The friction coefficient is related to surface coating, material properties, and surface roughness. For studying the influence of friction coefficient on the damping effect, the amplitude-frequency response curves of beam 1 for different friction coefficients are calculated for $F=300 \mathrm{~N}$, as shown in Figure 18. The results show that the resonance amplitude of the beam increases as the friction coefficient increases. The frequency range of the slipping phenomenon also reduces continuously. This indicates that the beam root is in a stationary sticking state at a higher friction coefficient. Moreover, it also points out that the lower friction coefficient shows a better damping effect. Consequently, when designing the rotating beam with contact interface, the contact parameters such as the appropriate surface coating should be considered, and the optimal value of contact surface's friction coefficient should be guaranteed to suppress the beam's vibration.

A focus on the time series of responses for beam 1 to beam 6 allows a better understanding of the influence of friction coefficient on the nonlinear vibration characteristics of the coupling system. Figures 19(a) and 20(a) firstly illustrate the time series of the response of beam 1 to beam 6 for $\mu=0.3$, and the corresponding operation condition is $\omega=290 \mathrm{~Hz}, F=300 \mathrm{~N}$, and $\Omega=200 \mathrm{rad} / \mathrm{s}$. Besides, Figures 19 and 20 also display the response curves and spectrum plots of beams 1 and 2 .

The results in Figure 19(a) show that there are still traveling waves propagating in the same direction. However, the phase lag of the traveling wave in Figure 20(a) becomes unclear due to the nonlinearity of dry friction force. And the response curves, especially the response curves of the beam at root, exhibit conspicuous nonlinear characteristics. Moreover, the $3 \mathrm{x}$ and $5 \mathrm{x}$ also appear in the spectrum plot. These phenomena reveal that the slipping phenomenon of dry friction occurs, and dry friction plays the role of dissipating vibration energy and attenuating the vibration amplitude.

The analysis is also performed for response characteristics of the beam for $\mu=0.8$ in Figures 21 and 22. It can be seen that the response of beam 1 to beam 6 is a traveling wave with a clear characteristic diagonal pattern. The clear phase lag in time series of response points out that the nonlinearity disappears. The response curves present a simple harmonic, and there is only $1 \mathrm{x}$ in the spectrum plot. These response characteristics show that there are no nonlinear phenomena. Besides, the response amplitude of the beam greatly increases, compared to that of $\mu=0.3$. Thus, it can be inferred that the beam root is under a stationary sticking state, and the dry friction does not dissipate the vibration energy of the beam.

Then, the computation of the time series of contact force and beam response permits us to understand the effects of friction coefficient better. A dual $y$-axis is applied to plot the time series of dry friction force and beam response in Figures 23(a)-23(c), respectively. In Figures 23(d)-23(f) show the hysteresis curves of contact force for $0.3,0.6$, and 0.8 , respectively. In the case of $\mu=0.3$ and $\mu=0.6$, contact force increases firstly in sticking state and then keeps in constant while it reaches the slipping state. The comparison results show that the maximum of dry friction force will be shifted by friction coefficient. Corresponding contact force curve gradually shifts toward a simple harmonic for the higher friction coefficient. The hysteresis curve of dry friction gradually evolves from the closed-loop of the parallelogram to a straight line. The area of the hysteresis loop in Figure 23 reveals that the energy dissipation of dry friction is more when the friction coefficient is 0.3 . For $\mu=0.8$, the contact force and hysteresis loop of contact DOFs exhibit the harmonic form and the straight line, respectively. This phenomenon points out that there is no energy dissipation by dry friction for a high friction coefficient.

\section{Conclusion}

The nonlinear characteristics of a coupling disk-beam model subject to dry friction have been investigated. The mode function of a continuum beam with the dovetail interface feature is developed and verified to simulate the vibration of the beam. The present analysis mainly focuses on the effects of different parameters on the nonlinear characteristics of 
the disk-beam system. Then, further analysis yields an overview of the influence of different parameters on the damping effect. Some conclusions can be summarized as follows:

(1) At the low rotational speed, a certain softening nonlinearity occurs. Then, the nonlinearity will gradually disappear at a higher rotational speed. The analysis of the influence of rotational speed on dry friction force concludes that dry friction force shifts toward a linear force at a high rotational speed.

(2) The resonance frequency shifts toward lower frequency as the excitation level increases, revealing that the dry friction contact is softening nonlinearity. Further analysis of the dry friction force shows that the maximum value is not affected by the excitation level, while the time at maximum will decrease as the excitation level increases. Besides, the resonance amplitude still gradually increases, although the energy dissipated by dry friction increases with the excitation level.

(3) In the analysis of the friction coefficient, it is known that the flexible disk imposes a more significant effect on the beam's response characteristics at a high excitation level and rotational speed. Besides, the dry friction force will shift toward a linear force at a high friction coefficient. Consequently, the friction coefficient imposes a significant influence on the damping effect of dry friction.

\section{Appendix}

\section{A: List of Symbols}

$A_{\mathrm{b}}$ : Cross-section area of the beam

$D$ : The bending rigidity of flexible disk

$E_{\mathrm{D}}$ : Young's modulus of the disk

$E_{\mathrm{b}}$ : Young's modulus of beam

$h_{\mathrm{D}}$ : Thickness of the disk

$I_{\mathrm{b}}$ : Area moment of inertia of the beam

$J_{\text {pd }}$ : Polar moment of inertia for disk

$k_{\mathrm{t}}$ : Contact stiffness

$L_{\mathrm{b}}$ : Beam length

$m_{\mathrm{D}}$ : Mass of the disk

$N$ : Normal force of contact interface

$N_{\mathrm{b}}$ : The number of beam

$\mathbf{q}_{\mathrm{u}}, \mathbf{q}_{\mathrm{v}}$ : Generalized vector of the beam

$\mathbf{Q}_{\xi}, \mathbf{Q}_{\eta}$ : Generalized vector of the disk

$R_{\mathrm{S}}$ : Inner radius of the disk

$R_{\mathrm{D}}$ : Outer radius of the disk

$u_{\mathrm{D}}$ : Disk's transverse displacement

$u$ : Beam displacements with respect to the $x_{\mathrm{b}}$ axis

$v$ : Beam displacements with respect to the $y_{\mathrm{b}}$ axis

$\mathbf{U}, \mathbf{V}$ : The mode shape vector of the beam

$\Phi_{\mathrm{D}_{\mathrm{c}}}, \Phi_{\mathrm{D}_{\mathrm{s}}}$ : The mode shape vector of the flexible disk
$\rho_{\mathrm{D}}$ : Material density of the disk

$\rho_{\mathrm{b}}$ : Beam mass density

$\nu_{\mathrm{D}}$ : Poisson's ratio

$\beta$ : Stagger angle of the beam

$\Phi, \eta$ : Tenon angle of the contact interface

$\mu$ : Friction coefficient of the contact interface

$\sigma_{\mathrm{r}}, \sigma_{\theta}$ : Disk's initial stresses in radial and circumferential directions

$\vartheta_{i}$ : The position angle of $i^{\text {th }}$ beam $\left(\Omega t+(i-1) 2 \pi / N_{\mathrm{b}}\right)$

$\Omega$ : Rotational speed

Subscripts

()$_{\mathrm{b}}$ : Beam bending

()$_{\mathrm{D}}$ : Disk transverse.

\section{B: Matrices Elements}

$$
\mathbf{K}_{\mathrm{e}}=\left[\begin{array}{cccc}
\mathbf{K}_{\mathrm{D}}^{\mathrm{e}} & \mathbf{0} & \cdots & \mathbf{0} \\
\mathbf{0} & \mathbf{K}_{\mathrm{B}_{1}}^{\mathrm{e}} & \cdots & \mathbf{0} \\
\vdots & \vdots & \ddots & \vdots \\
\mathbf{0} & \mathbf{0} & \cdots & \mathbf{K}_{\mathrm{B}_{N_{\mathrm{b}}}}^{\mathrm{e}}
\end{array}\right],
$$$$
\mathbf{K}_{\Omega}=\left[\begin{array}{cccc}
\mathbf{K}_{\mathrm{D}}^{\Omega} & \mathbf{K}_{\mathrm{DB}}^{\Omega} & \cdots & \mathbf{K}_{\mathrm{DB}}^{\Omega} \\
\mathbf{K}_{\mathrm{DB}}^{\Omega \mathrm{T}} & \mathbf{K}_{\mathrm{B}_{1}}^{\Omega} & \cdots & \mathbf{0} \\
\vdots & \vdots & \ddots & \vdots \\
\mathbf{K}_{\mathrm{DB}}^{\Omega \mathrm{T}} & \mathbf{0} & \cdots & \mathbf{K}_{\mathrm{B}_{N_{\mathrm{b}}}}^{\Omega}
\end{array}\right],
$$

$$
\mathbf{G}=\left[\begin{array}{cccc}
\mathbf{0} & \mathbf{0} & \cdots & \mathbf{0} \\
\mathbf{0} & \mathbf{G}_{\mathrm{B}_{1}} & \cdots & \mathbf{0} \\
\vdots & \vdots & \ddots & \vdots \\
\mathbf{0} & \mathbf{0} & \cdots & \mathbf{G}_{\mathrm{B}_{N_{\mathrm{b}}}}
\end{array}\right]
$$

$$
\mathbf{M}_{\mathrm{D}}=\left[\begin{array}{cc}
\mathbf{M}_{\mathrm{D} 1} & \mathbf{0} \\
\mathbf{0} & \mathbf{M}_{\mathrm{D} 2}
\end{array}\right] \text {, }
$$




$$
\begin{aligned}
& \mathbf{M}_{\mathrm{B}}=\left[\begin{array}{cc}
\mathbf{M}_{\mathrm{Bu}} & \mathbf{0} \\
\mathbf{0} & \mathbf{M}_{\mathrm{Bv}}
\end{array}\right], \\
& \mathbf{M}_{\mathrm{DB}}=\left[\begin{array}{ll}
\mathbf{0} & \mathbf{M}_{\mathrm{DB} 1} \\
\mathbf{0} & \mathbf{M}_{\mathrm{DB} 2}
\end{array}\right] \text {, } \\
& \mathbf{K}_{\mathrm{D}}^{\mathrm{e}}=\left[\begin{array}{cc}
\mathbf{K}_{\mathrm{D} 1}^{\mathrm{e}} & \mathbf{0} \\
\mathbf{0} & \mathbf{K}_{\mathrm{D} 2}^{\mathrm{e}}
\end{array}\right] \text {, } \\
& \mathbf{K}_{\mathrm{B}}^{\mathrm{e}}=\left[\begin{array}{cc}
\mathbf{K}_{\mathrm{B} 1}^{\mathrm{e}} & \mathbf{0} \\
\mathbf{0} & \mathbf{K}_{\mathrm{B} 2}^{\mathrm{e}}
\end{array}\right] \text {, } \\
& \mathbf{K}_{\mathrm{D}}^{\Omega}=\left[\begin{array}{cc}
\mathbf{K}_{\mathrm{D} 1}^{\Omega} & \mathbf{0} \\
\mathbf{0} & \mathbf{K}_{\mathrm{D} 2}^{\Omega}
\end{array}\right] \text {, } \\
& \mathbf{K}_{\mathrm{B}}^{\Omega}=\left[\begin{array}{cc}
\mathbf{K}_{\mathrm{Bu}}^{\Omega} & \mathbf{0} \\
\mathbf{0} & \mathbf{K}_{\mathrm{Bv}}^{\Omega}
\end{array}\right] \text {, } \\
& \mathbf{K}_{\mathrm{DB}}^{\Omega}=\left[\begin{array}{l}
\mathbf{K}_{\mathrm{DB} 1}^{\Omega} \\
\mathbf{K}_{\mathrm{DB} 2}^{\Omega}
\end{array}\right] \text {, } \\
& \mathbf{G}_{\mathrm{B}}=\left[\begin{array}{cc}
\mathbf{0} & -\mathbf{G}_{\mathrm{B} 1} \\
\mathbf{G}_{\mathrm{B} 1}^{\mathrm{T}} & \mathbf{0}
\end{array}\right] \text {, } \\
& \mathbf{M}_{\mathrm{D} 1}=\rho_{\mathrm{D}} h_{\mathrm{D}} \int_{0}^{2 \pi} \int_{\mathrm{Rs}}^{\mathrm{RD}} \boldsymbol{\Phi}_{\mathrm{D}_{\mathrm{c}}}^{\mathrm{T}}(r, \theta) \boldsymbol{\Phi}_{\mathrm{D}_{\mathrm{c}}}(r, \theta) r \mathrm{D} r \mathrm{D} \theta \\
& +\sum_{i=1}^{N_{\mathrm{b}}} \rho_{\mathrm{b}} A_{\mathrm{b}} \int_{0}^{\mathrm{Lb}}\left\{\boldsymbol{\Phi}_{\mathrm{D}_{\mathrm{C}}}\left(R_{\mathrm{D}}, \vartheta_{i}\right)+\left.x \frac{\partial \boldsymbol{\Phi}_{\mathrm{D}_{\mathrm{C}}}(r, \theta)}{\partial r}\right|_{r=R_{\mathrm{D}}, \theta=\vartheta_{i}}\right\}^{\mathrm{T}} \\
& \cdot\left\{\Phi_{\mathrm{D}_{\mathrm{C}}}\left(R_{\mathrm{D}}, \vartheta_{i}\right)+\left.x \frac{\partial \boldsymbol{\Phi}_{\mathrm{D}_{\mathrm{C}}}(r, \theta)}{\partial r}\right|_{r=R_{\mathrm{D}}, \theta=\vartheta_{i}}\right\} \mathrm{D} x, \\
& \mathbf{K}_{\mathrm{D} 1}^{e}=D \int_{0}^{2 \pi} \int_{\mathrm{Rs}}^{\mathrm{RD}}\left[\nabla^{2} \boldsymbol{\Phi}_{\mathrm{D}_{\mathrm{c}}}(r, \theta)\right]^{\mathrm{T}}\left[\nabla^{2} \boldsymbol{\Phi}_{\mathrm{D}_{\mathrm{c}}}(r, \theta)\right] r \mathrm{~d} r \mathrm{~d} \theta \\
& -2\left(1-v_{\mathrm{D}}\right) D \int_{0}^{2 \pi} \int_{\mathrm{Rs}}^{\mathrm{RD}}\left[\frac{\partial^{2} \boldsymbol{\Phi}_{\mathrm{D}_{\mathrm{c}}}(r, \theta)}{\partial r^{2}}\right]^{\mathrm{T}}\left[\frac{\partial \boldsymbol{\Phi}_{\mathrm{D}_{\mathrm{c}}}(r, \theta)}{\partial r}\right. \\
& \left.+\frac{1}{r} \frac{\partial^{2} \boldsymbol{\Phi}_{\mathrm{D}_{\mathrm{c}}}(r, \theta)}{\partial \theta^{2}}\right] \mathrm{d} r \mathrm{~d} \theta+2\left(1-v_{\mathrm{D}}\right) D \int_{0}^{2 \pi} \\
& \cdot \int_{\mathrm{Rs}}^{\mathrm{RD}} \frac{1}{r}\left[\frac{\partial^{2} \boldsymbol{\Phi}_{\mathrm{D}_{\mathrm{c}}}(r, \theta)}{\partial r \partial \theta}-\frac{1}{r} \frac{\partial \boldsymbol{\Phi}_{\mathrm{D}_{c}}(r, \theta)}{\partial \theta}\right]^{\mathrm{T}} \\
& \cdot\left[\frac{\partial^{2} \boldsymbol{\Phi}_{\mathrm{D}_{\mathrm{c}}}(r, \theta)}{\partial r \partial \theta}-\frac{1}{r} \frac{\partial \boldsymbol{\Phi}_{\mathrm{D}_{\mathrm{c}}}(r, \theta)}{\partial \theta}\right] \mathrm{d} r \mathrm{~d} \theta, \\
& \mathbf{K}_{\mathrm{D} 2}^{e}=D \int_{0}^{2 \pi} \int_{\mathrm{Rs}}^{\mathrm{RD}}\left[\nabla^{2} \boldsymbol{\Phi}_{\mathrm{D}_{\mathrm{s}}}(r, \theta)\right]^{\mathrm{T}}\left[\nabla^{2} \boldsymbol{\Phi}_{\mathrm{D}_{\mathrm{s}}}(r, \theta)\right] r \mathrm{~d} r \mathrm{~d} \theta \\
& -2\left(1-v_{\mathrm{D}}\right) D \int_{0}^{2 \pi} \\
& \cdot \int_{\mathrm{Rs}}^{\mathrm{RD}}\left[\frac{\partial^{2} \boldsymbol{\Phi}_{\mathrm{D}_{\mathrm{s}}}(r, \theta)}{\partial r^{2}}\right]^{\mathrm{T}}\left[\frac{\partial \boldsymbol{\Phi}_{\mathrm{D}_{\mathrm{s}}}(r, \theta)}{\partial r}+\frac{1}{r} \frac{\partial^{2} \boldsymbol{\Phi}_{\mathrm{D}_{\mathrm{s}}}(r, \theta)}{\partial \theta^{2}}\right] \mathrm{d} r \mathrm{~d} \theta \\
& +2\left(1-v_{\mathrm{D}}\right) D \int_{0}^{2 \pi} \int_{\mathrm{Rs}}^{\mathrm{RD}} \frac{1}{r}\left[\frac{\partial^{2} \boldsymbol{\Phi}_{\mathrm{D}_{s}}(r, \theta)}{\partial r \partial \theta}-\frac{1}{r} \frac{\partial \boldsymbol{\Phi}_{\mathrm{D}_{\mathrm{s}}}(r, \theta)}{\partial \theta}\right]^{\mathrm{T}} \\
& \cdot\left[\frac{\partial^{2} \Phi_{\mathrm{D}_{\mathrm{s}}}(r, \theta)}{\partial r \partial \theta}-\frac{1}{r} \frac{\partial \Phi_{\mathrm{D}_{\mathrm{s}}}(r, \theta)}{\partial \theta}\right] \mathrm{d} r \mathrm{~d} \theta, \\
& \mathbf{K}_{\mathrm{B} 1}^{\mathrm{e}}=E_{\mathrm{b}} A_{\mathrm{b}} \int_{0}^{L_{\mathrm{b}}} \mathbf{U}^{\prime \mathrm{T}} \mathbf{U d} x \text {, } \\
& \mathbf{K}_{\mathrm{B} 2}^{\mathrm{e}}=E_{\mathrm{b}} I_{\mathrm{b}} \int_{0}^{L_{\mathrm{b}}} \mathbf{V}^{\prime \prime \prime} \mathrm{T} \mathbf{V}^{\prime \prime} \mathrm{d} x \text {, } \\
& \mathbf{M}_{\mathrm{D} 2}=\rho_{\mathrm{D}} h_{\mathrm{D}} \int_{0}^{2 \pi} \int_{\mathrm{Rs}}^{\mathrm{RD}} \boldsymbol{\Phi}_{\mathrm{D}_{\mathrm{S}}}^{\mathrm{T}}(r, \theta) \boldsymbol{\Phi}_{\mathrm{D}_{\mathrm{S}}}(r, \theta) r \mathrm{D} r \mathrm{D} \theta \\
& +\sum_{i=1}^{N_{\mathrm{b}}} \rho_{\mathrm{b}} A_{\mathrm{b}} \int_{0}^{\mathrm{Lb}}\left\{\boldsymbol{\Phi}_{\mathrm{D}_{\mathrm{S}}}\left(R_{\mathrm{D}}, \vartheta_{i}\right)+\left.x \frac{\partial \boldsymbol{\Phi}_{D_{S}}(r, \theta)}{\partial r}\right|_{r=R_{\mathrm{D}}, \theta=\vartheta_{i}}\right\}^{\mathrm{T}} \\
& \mathbf{K}_{\mathrm{D} 1}^{\Omega}=h_{D} \int_{0}^{2 \pi} \int_{\mathrm{Rs}}^{\mathrm{RD}}\left[\sigma_{r}\left(\frac{\partial \boldsymbol{\Phi}_{\mathrm{D}_{c}}(r, \theta)}{\partial r}\right)^{\mathrm{T}} \frac{\partial \boldsymbol{\Phi}_{\mathrm{D}_{c}}(r, \theta)}{\partial r}\right. \\
& \left.+\frac{\sigma_{\theta}}{r^{2}}\left(\frac{\partial \Phi_{\mathrm{D}_{\mathrm{c}}}(r, \theta)}{\partial \theta}\right)^{\mathrm{T}} \frac{\partial \Phi_{\mathrm{D}_{c}}(r, \theta)}{\partial \theta}\right] r \mathrm{~d} r \mathrm{~d} \theta \\
& \cdot\left\{\boldsymbol{\Phi}_{\mathrm{D}_{\mathrm{S}}}\left(R_{\mathrm{D}}, \vartheta_{i}\right)+\left.x \frac{\partial \boldsymbol{\Phi}_{D_{S}}(r, \theta)}{\partial r}\right|_{r=R_{\mathrm{D}}, \theta=\vartheta_{i}}\right\} \mathrm{D} x, \\
& +\sum_{i=1}^{N_{\mathrm{b}}} \frac{1}{2} \rho_{\mathrm{b}} A_{\mathrm{b}} \int_{0}^{L_{\mathrm{b}}}\left[L_{\mathrm{b}}^{2}-x^{2}+2 R_{\mathrm{D}}\left(L_{\mathrm{b}}-x\right)\right] \\
& \mathbf{M}_{\mathrm{Bu}}=\rho_{\mathrm{b}} A_{\mathrm{b}} \int_{0}^{\mathrm{Lb}} \mathbf{U}^{\mathrm{T}} \mathrm{UD} x, \\
& \mathbf{M}_{\mathrm{Bv}}=\rho_{\mathrm{b}} A_{\mathrm{b}} \int_{0}^{\mathrm{Lb}} \mathbf{V}^{\mathrm{T}} \mathbf{V D} x, \\
& \mathbf{M}_{\mathrm{DB} 1}=-\rho_{\mathrm{b}} A_{\mathrm{b}}\left\{\int_{0}^{\mathrm{Lb}} \boldsymbol{\Phi}_{\mathrm{D}_{\mathrm{C}}}^{\mathrm{T}}\left(R_{\mathrm{D}}, \vartheta_{i}\right) \mathbf{V D} x\right. \\
& \left.+\left.\int_{0}^{\mathrm{Lb}} \frac{\partial \boldsymbol{\Phi}_{\mathrm{D}_{\mathrm{C}}}^{\mathrm{T}}(r, \theta)}{\partial r}\right|_{r=R_{\mathrm{D}}, \theta=n 9_{i}} x \mathrm{VD} x\right\} \sin \beta, \\
& \left.\cdot\left(\frac{\partial \Phi_{\mathrm{D}_{\mathrm{c}}}(r, \theta)}{\partial r}\right)^{\mathrm{T}} \frac{\partial \Phi_{\mathrm{D}_{\mathrm{c}}}(r, \theta)}{\partial r}\right|_{r=R_{\mathrm{D}}, \theta=\vartheta_{i}} \mathrm{~d} x, \\
& \mathbf{K}_{\mathrm{D} 2}^{\Omega}=h_{\mathrm{D}} \int_{0}^{2 \pi} \int_{\mathrm{Rs}}^{\mathrm{RD}}\left[\sigma_{r}\left(\frac{\partial \Phi_{D_{s}}(r, \theta)}{\partial r}\right)^{\mathrm{T}} \frac{\partial \Phi_{\mathrm{D}_{s}}(r, \theta)}{\partial r}\right. \\
& \left.+\frac{\sigma_{\theta}}{r^{2}}\left(\frac{\partial \Phi_{\mathrm{D}_{\mathrm{s}}}(r, \theta)}{\partial \theta}\right)^{\mathrm{T}} \frac{\partial \Phi_{\mathrm{D}_{\mathrm{s}}}(r, \theta)}{\partial \theta}\right] r \mathrm{~d} r \mathrm{~d} \theta \\
& +\sum_{i=1}^{N_{\mathrm{b}}} \frac{1}{2} \rho_{\mathrm{b}} A_{\mathrm{b}} \int_{0}^{L_{\mathrm{b}}}\left[L_{\mathrm{b}}^{2}-x^{2}+2 R_{\mathrm{D}}\left(L_{\mathrm{b}}-x\right)\right] \\
& \mathbf{M}_{\mathrm{DB} 1}=-\rho_{\mathrm{b}} A_{\mathrm{b}}\left\{\int_{0}^{\mathrm{Lb}} \boldsymbol{\Phi}_{\mathrm{D}_{\mathrm{C}}}^{\mathrm{T}}\left(R_{\mathrm{D}}, \vartheta_{i}\right) \mathbf{V D} x\right. \\
& \left.+\left.\int_{0}^{\mathrm{Lb}} \frac{\partial \boldsymbol{\Phi}_{\mathrm{D}_{\mathrm{C}}}^{\mathrm{T}}(r, \theta)}{\partial r}\right|_{r=R_{\mathrm{D}}, \theta=n \vartheta_{i}} x \mathbf{V D} x\right\} \sin \beta, \\
& \left.\cdot\left(\frac{\partial \Phi_{\mathrm{D}_{\mathrm{s}}}(r, \theta)}{\partial r}\right)^{\mathrm{T}} \frac{\partial \Phi_{\mathrm{D}_{\mathrm{s}}}(r, \theta)}{\partial r}\right|_{r=R_{\mathrm{D}}, \theta=9_{i}} \mathrm{~d} x \\
& \mathbf{K}_{\mathrm{Bu}}^{\Omega}=-\rho_{\mathrm{b}} A_{\mathrm{b}} \int_{0}^{L_{\mathrm{b}}} \mathbf{U}^{\mathrm{T}} \mathbf{U D} x,
\end{aligned}
$$




$$
\begin{aligned}
\mathbf{K}_{\mathrm{Bv}}^{\Omega}= & \frac{1}{2} \rho_{\mathrm{b}} A_{\mathrm{b}} \int_{0}^{L_{\mathrm{b}}}\left\{L_{\mathrm{b}}^{2}-x^{2}+2 R_{\mathrm{D}}\left(L_{\mathrm{b}}-x\right)\right\} \mathbf{V}^{\prime \mathrm{T}} \mathbf{V}^{\prime} \mathrm{D} x \\
& -\rho_{\mathrm{b}} A_{\mathrm{b}} \int_{0}^{L_{\mathrm{b}}} \mathbf{V}^{\mathrm{T}} \mathbf{V D} x(\cos \beta)^{2}, \\
\mathbf{K}_{\mathrm{DB} 1}^{\Omega}= & -\left.\frac{1}{2} \rho_{\mathrm{b}} A_{\mathrm{b}} \int_{0}^{L_{\mathrm{b}}}\left\{L_{\mathrm{b}}^{2}-x^{2}+2 R_{\mathrm{D}}\left(L_{\mathrm{b}}-x\right)\right\} \frac{\partial \Phi_{\mathrm{D}_{\mathrm{C}}}^{\mathrm{T}}(r, \theta)}{\partial r}\right|_{r=R_{\mathrm{D}}, \theta=\vartheta_{i}} \\
& \cdot \mathbf{V}^{\prime} \mathrm{D} x \sin \beta-\left.\rho_{\mathrm{b}} A_{\mathrm{b}} \int_{0}^{L_{\mathrm{b}}}\left(R_{\mathrm{D}}+x\right) \frac{\partial \Phi_{\mathrm{D}_{\mathrm{C}}}^{\mathrm{T}}(r, \theta)}{\partial r}\right|_{r=R_{\mathrm{D}}, \theta=\vartheta_{i}}
\end{aligned}
$$$$
\text { - VD } x \sin \beta \text {, }
$$$$
\begin{aligned}
\mathbf{K}_{\mathrm{DB} 2}^{\Omega}= & -\left.\frac{1}{2} \rho_{\mathrm{b}} A_{\mathrm{b}} \int_{0}^{L_{\mathrm{b}}}\left\{L_{\mathrm{b}}^{2}-x^{2}+2 R_{\mathrm{D}}\left(L_{\mathrm{b}}-x\right)\right\} \frac{\partial \Phi_{\mathrm{D}_{\mathrm{s}}}^{\mathrm{T}}(r, \theta)}{\partial r}\right|_{r=R_{\mathrm{D}}, \theta=\vartheta_{i}} \\
& \cdot \mathbf{V}^{\prime} \mathrm{D} x \sin \beta-\left.\rho_{\mathrm{b}} A_{\mathrm{b}} \int_{0}^{L_{\mathrm{b}}}\left(R_{\mathrm{D}}+x\right) \frac{\partial \boldsymbol{\Phi}_{\mathrm{D}_{\mathrm{s}}}^{\mathrm{T}}(r, \theta)}{\partial r}\right|_{r=R_{\mathrm{D}}, \theta=\vartheta_{i}}
\end{aligned}
$$$$
\text { - VD } x \sin \beta \text {, }
$$$$
\mathbf{G}_{\mathrm{B} 1}=2 \rho_{\mathrm{b}} A_{\mathrm{b}} \int_{0}^{L_{\mathrm{b}}} \mathbf{U}^{\mathrm{T}} \mathbf{V D} x \cos \beta,
$$$$
\mathbf{A}_{0}=\left[\begin{array}{ccc}
\cos (\Omega t) & -\sin (\Omega t) & 0 \\
\sin (\Omega t) & \cos (\Omega t) & 0 \\
0 & 0 & 1
\end{array}\right],
$$$$
\mathbf{A}_{1}=\left[\begin{array}{ccc}
\cos \vartheta_{i} & -\sin \vartheta_{i} & 0 \\
\sin \vartheta_{i} & \cos \vartheta_{i} & 0 \\
0 & 0 & 1
\end{array}\right] \text {, }
$$$$
\mathbf{A}_{2}=\left[\begin{array}{ccc}
\cos u_{\mathrm{D}}^{\prime} & 0 & -\sin u_{\mathrm{D}}^{\prime} \\
0 & 1 & 0 \\
\sin u_{\mathrm{D}}^{\prime} & 0 & \cos u_{\mathrm{D}}^{\prime}
\end{array}\right] \text {, }
$$$$
\mathbf{A}_{3}=\left[\begin{array}{ccc}
1 & 0 & 0 \\
0 & \cos \beta & \sin \beta \\
0 & -\sin \beta & \cos \beta
\end{array}\right] \text {, }
$$

\section{Data Availability}

All data generated or analyzed during this study are included in this article. But the processed data required to reproduce these findings cannot be shared at this time due to legal or ethical reasons.

\section{Conflicts of Interest}

The authors declare that there are no conflicts of interest regarding the publication of this article.

\section{Acknowledgments}

This work was supported by the National Natural Science Foundation of China (no. 51575093) and the Fundamental
Research Funds for the Central Universities (nos. N180313008, N182410007-06, and N170302001).

\section{References}

[1] A. V. Srinivasan and D. G. Cutts, "Dry friction damping mechanisms in engine blades," Journal of Engineering for Power, vol. 105, no. 2, pp. 332-341, 1983.

[2] M. Afzal, I. Lopez Arteaga, and L. Kari, "An analytical calculation of the Jacobian matrix for 3D friction contact model applied to turbine blade shroud contact," Computers \& Structures, vol. 177, pp. 204-217, 2016.

[3] Z. Qin, Q. Han, and F. Chu, "Analytical model of bolted diskdrum joints and its application to dynamic analysis of jointed rotor," Proceedings of the Institution of Mechanical Engineers, Part C: Journal of Mechanical Engineering Science, vol. 228, no. 4, pp. 646-663, 2014.

[4] Z. Qin, Q. Han, and F. Chu, "Bolt loosening at rotating joint interface and its influence on rotor dynamics," Engineering Failure Analysis, vol. 59, pp. 456-466, 2016.

[5] W. Ostachowicz, "Forced vibrations of a beam including dry friction dampers," Computers \& Structures, vol. 33, no. 3, pp. 851-858, 1989.

[6] A. Sinha and J. H. Griffin, "Effects of static friction on the forced response of frictionally damped turbine blades," Journal of Engineering for Gas Turbines and Power, vol. 106, no. 1, pp. 65-69, 1984.

[7] C. H. Menq and J. H. Griffin, "A comparison of transient and steady state finite element analyses of the forced response of a frictionally damped beam," Journal of Vibration and Acoustics, vol. 107, no. 1, p. 106, 1985.

[8] F. C. Li, C. Z. Shen, F. B. Zhong et al., "Study on the nonlinear characteristics of a rotating flexible blade with dovetail interface feature," Shock and Vibration, vol. 2018, Article ID 4923898, 13 pages, 2018.

[9] C.-H. Menq, J. Bielak, and J. H. Griffin, "The influence of microslip on vibratory response, part I: a new microslip model," Journal of Sound and Vibration, vol. 107, no. 2, pp. 279-293, 1986.

[10] E. Cigeroglu, W. Lu, and C.-H. Menq, "One-dimensional dynamic microslip friction model," Journal of Sound and Vibration, vol. 292, no. 3-5, pp. 881-898, 2006.

[11] C.-H. Menq, J. H. Griffin, and J. Bielak, "The influence of microslip on vibratory response, part II: a comparison with experimental results," Journal of Sound and Vibration, vol. 107, no. 2, pp. 295-307, 1986.

[12] T. Berruti, S. Filippi, M. M. Gola et al., "Friction damping of interlocked vane segments: experimental results," ASME, vol. 124, no. 4, pp. 891-898, 2001.

[13] S. Filippi, A. Akay, and M. M. Gola, "Measurement of tangential contact hysteresis during microslip," Journal of Tribology, vol. 126, no. 3, pp. 482-489, 2004.

[14] C.-f. Li, H.-x. She, W. Liu, and B.-c. Wen, "The influence of shaft's bending on the coupling vibration of a flexible bladerotor system," Mathematical Problems in Engineering, vol. 2017, Article ID 7313956, pp. 1-19, 2017.

[15] F. C. Li, X. H. She, S. Q. Tang et al., "The effect of blade vibration on the nonlinear characteristics of rotor-bearing system supported by nonlinear suspension," Nonlinear Dynamics, vol. 89, no. 1, pp. 1-24, 2017.

[16] Q. B. Li, H. Ma, X. Yu et al., "Nonlinear vibration and dynamic stability analysis of rotor-blade system with nonlinear supports," Archive of Applied Mechanics, vol. 89, no. 7, pp. 1375-1402, 2019. 
[17] E. P. Petrov and D. J. Ewins, "Effects of damping and varying contact area at blade-disk joints in forced response analysis of bladed disk assemblies," Journal of Turbomachinery, vol. 128, no. 2, pp. 403-410, 2006.

[18] D. Charleux, C. Gibert, F. Thouverez et al., "Numerical and experimental study of friction damping blade attachments of rotating bladed disks," International Journal of Rotating Machinery, vol. 2006, Article ID 71302, 13 pages, 2006.

[19] D. Laxalde, L. Salles, L. Blanc et al., "Non-linear modal analysis for bladed disks with friction contact interfaces," in Proceedings of the Asme Turbo Expo Power for Land Sea and Air, pp. 457-467, 2008.

[20] H. Ma, D. Wang, X. Tai et al., "Vibration response analysis of blade-disk dovetail structure under blade tip rubbing condition," Journal of Vibration and Control, vol. 23, no. 2, pp. 252-271, 2015.

[21] M. Krack, L. Salles, and F. Thouverez, "Vibration prediction of bladed disks coupled by friction joints," Archives of Computational Methods in Engineering, vol. 24, no. 3, pp. 589-636, 2017.

[22] B. Shangguan, Z. Xu, Q. Wu et al., "Forced response prediction of blades with loosely assembled dovetail attachment by HBM," in Proceedings of the Asme Turbo Expo, pp. 421428, 2009, Orlando, FL, USA.

[23] S. Bo, Z. Xu, Y. Liu et al., "Experimental investigation on damping characteristics of blade with loosely assembled dovetail attachment," in Proceedings of the Asme Turbo Expo, pp. 837-843, Glasgow, UK, 2010.

[24] W. Gu and Z. Xu, "3D numerical friction contact model and its application to nonlinear blade damping," in Proceedings of the Asme Turbo Expo, 2010.

[25] W. W. Gu and Z. L. Xu, "Description of constraint force and prediction of vibration responses for dry friction damped blade," Zhendong Gongcheng Xuebao/Journal of Vibration Engineering, vol. 25, no. 1, pp. 64-67, 2012.

[26] Y. Liu, B. Shangguan, and Z. Xu, "A friction contact stiffness model of fractal geometry in forced response analysis of a shrouded blade," Nonlinear Dynamics, vol. 70, no. 3, pp. 2247-2257, 2012.

[27] M. Lassalle and C. M. Firrone, "A parametric study of limit cycle oscillation of a bladed disk caused by flutter and friction at the blade root joints," Journal of Fluids and Structures, vol. 76, pp. 349-366, 2018.

[28] E. Ciğeroğlu and H. N. Özgüven, "Nonlinear vibration analysis of bladed disks with dry friction dampers," Journal of Sound and Vibration, vol. 295, no. 3-5, pp. 1028-1043, 2006.

[29] C. Joannin, B. Chouvion, F. Thouverez et al., "Nonlinear modal analysis of mistuned periodic structures subjected to dry friction," Journal of Engineering for Gas Turbines and Power, vol. 138, no. 7, 2016.

[30] C. Joannin, B. Chouvion, F. Thouverez, J.-P. Ousty, and M. Mbaye, "A nonlinear component mode synthesis method for the computation of steady-state vibrations in non-conservative systems," Mechanical Systems and Signal Processing, vol. 83, pp. 75-92, 2017.

[31] H. She, C. Li, Q. Tang, and B. Wen, "The investigation of the coupled vibration in a flexible-disk blades system considering the influence of shaft bending vibration," Mechanical Systems and Signal Processing, vol. 111, pp. 545-569, 2018. 